\title{
Fortificaciones e implantación romana entre La Serena y la Vega del Guadiana: el Castejón de las Merchanas (Don Benito, Badajoz) y su contexto territorial
}

\section{Fortifications and Roman intervention between La Serena and the Guadiana Basin: the Castejón de las Merchanas (Don Benito, Badajoz) and its territorial context}

\author{
Victorino Mayoral Herrera \\ Sebastián Celestino Pérez \\ Ernesto Salas Tovar \\ Macarena Bustamante Álvarez \\ Instituto de Arqueología-Mérida \\ (CSIC-Junta de Extremadura-Consorcio de Mérida)
}

\section{RESUMEN}

El Castejón de las Merchanas es un asentamiento fortificado que se localiza en el curso medio del valle del río Guadamez (Don Benito, Badajoz, España), en los límites de la comarca de La Serena. El buen estado de conservación y la monumentalidad de sus restos hacen que una labor exhaustiva de documentación ofrezca un gran caudal de datos sobre su estructura, funcionalidad y posible adscripción cronológica. Los resultados de dicha labor son confrontados con el conocimiento que actualmente se tiene de las llamadas fortificaciones en altura de la Serena, analizándose sus criterios de localización, diseño, técnica constructiva y materiales arqueológicos. Se propone un modelo de control estratégico del territorio y su contextualización en el proceso de «romanización» del suroeste peninsular.

\section{SUMMARY}

The Castejón de las Merchanas is a fortified settlement located in the Guadamez valley in the margins of the Serena region (Don Benito, Badajoz, Spain). Its good state of preservation and the monumentality of the visible remains made it worthwhile to develop a thorough recording effort in order to improve our knowledge of the structure, functionality and chronology of the site. The results of this effort are confronted with the knowledge we currently have of the fortifications in a regional framework, analyzing their locational criteria, design, building techniques and archaeological finds. We propose a model of strategic control of the territory and its contextualization in the process of «Romanization» in southwestern Spain.
PALABRAS CLAVE: Fortificaciones, romanización, La Serena, arqueología del territorio.

KEYWORDS: fortifications, romanization, La Serena, archaeology of territory.

1. PAISAJE, FORTIFICACIONES Y PROCESO ROMANIZADOR: NUEVOS ELEMENTOS PARA LA DISCUSIÓN

El estudio de las fortificaciones y construcciones de gran aparejo documentadas en amplias áreas del suroeste y sur peninsular constituye uno de los temas más largamente debatido y aún abierto, dentro del problema general de los modelos de ocupación del paisaje durante la transición entre la protohistoria y el período romano. Prueba de ello es la celebración en los últimos 10 años de tres encuentros científicos centrados sobre esta temática específica en la Península Ibérica (Morillo, Cadiou y Hourcade (eds.) 2003; Moret y Chapa (eds.) 2004 y Mayoral y Celestino (eds.) 2010). En estas referencias puede encontrar el lector una contextualización general de la cuestión que centra el presente trabajo. Aquí nos limitaremos a esbozar algunos puntos fundamentales 
de esta discusión. La multiplicación de trabajos recientes se ha traducido en una clarificación de aspectos clave para entender el fenómeno. Esto es así, en primer lugar, respecto a la presentación de resultados específicos, poniendo de relieve la existencia de este tipo de asentamientos en determinadas áreas donde no se conocían, y aportando también datos de excavación que son esenciales para ajustar cronológica y funcionalmente su interpretación. En segundo lugar, no han faltado esfuerzos de síntesis para clarificar conceptos y situar el tema en un marco histórico y geográfico más amplio. Seguimos a día de hoy argumentando acerca de la necesidad de una terminología concisa y homogénea para designar la variedad morfológica de las estructuras documentadas. Este empeño se encuentra en constante fricción con la creciente mejora del registro sobre la arquitectura de estos edificios. Aunque importante para el entendimiento colectivo, a nuestro modo de ver en ocasiones este debate tiende a asumir la búsqueda de nexos entre estrategias y formas de ocupación que obedecen a motivaciones diferenciadas. Esto puede desdibujar a veces la especificidad de cada contexto. Un elemento fundamental para templar este diálogo entre lo particular y lo general es la fijación de referencias cronológicas. Se ha asentado un consenso general acerca de la ausencia de continuidad entre estas estructuras y los tipos de asentamiento netamente indígenas, y la franja temporal queda acotada entre las dos centurias antes y después del cambio de era (Moret 2004).

Finalmente un problema íntimamente ligado al de la cronología es el del uso del espacio. La diversidad constatada multiplica las hipótesis sobre la funcionalidad, que oscila entre las variables de índole estratégico y defensivo y las relacionadas con la explotación económica. Sin embargo, cada vez resulta más claro que la explicación de las decisiones de localización y las soluciones constructivas adoptadas no puede fundamentarse en orientaciones monolíticas y excluyentes.

Uno de los sectores de la Península en el que es bien conocida la entidad del fenómeno de las fortificaciones ciclópeas es la comarca de La Serena, en la actual región de Extremadura (suroeste peninsular). Como se expone más adelante, desde los años 80 se han estudiado diversos aspectos de estas construcciones que reflejan vivamente la discusión general. Nuestro objetivo aquí es sencillamente aportar nuevos elementos a este debate, profundizando en el conocimiento de casos que han recibido poca atención y planteando un análisis desde nuevas perspectivas.

\section{LAS FORTIFICACIONES DE ALTURA EN LA SERENA: TRABAJOS PRECEDENTES}

Los sitios arqueológicos que son objeto del presente estudio ${ }^{1}$ forman parte de un conjunto conocido en la investigación arqueológica regional al menos desde los años ochenta del pasado siglo. En su tesis doctoral, Alonso Rodríguez (1996) incluye buena parte de ellos en un catálogo sobre asentamientos, en un principio relacionados con el poblamiento prerromano de la Baja Extremadura. Aunque estos datos permanecen inéditos, en sucesivas publicaciones han ido introduciéndose algunas referencias sobre el número, localización, denominación y características esenciales de estos sitios (Rodríguez Díaz y Ortiz Romero 1990: 51-54; Ortiz Romero y Rodríguez Díaz 1998: 264-265).

Sin embargo, el grueso de la investigación desarrollada en torno a las fortificaciones de la Serena se ha centrado en el estudio de los denominados recintos de llano (Rodríguez Díaz y Ortiz Romero 1986). Se trata de un grupo bastante homogéneo de edificios que se distribuyen principalmente a lo largo del valle del Ortigas cuyos emplazamientos, técnicas constructivas y registro material parecen definir un conjunto netamente diferenciado del de los sitios que aquí se analizan.

Al mismo tiempo, determinados sectores geográficos han recibido una mayor atención en función de circunstancias diversas. Así, Suárez de Venegas, como estudioso del poblamiento antiguo en las Vegas Altas del Guadiana, se ha ocupado junto con Rodríguez Díaz de catalogar y describir las fortificaciones de las sierras que delimitan por el sureste el término municipal de Don Benito (Venegas Sanz 1995). En el estudio monográfico sobre la historia de dicha población, dichos autores sitúan estas construcciones en el capítulo dedicado a la protohistoria, y sin embargo no llega a plantearse una hipótesis concreta respecto al papel de la población indígena en su creación. Se describen y clasifican siete casos, ajustándose al encuadre cronológico, funcional y cultural ofrecido

\footnotetext{
${ }^{1}$ Este trabajo ha sido realizado gracias al soporte de los siguientes proyectos de investigación: «Los paisajes agrarios del final de la Protohistoria en el suroeste peninsular: estudio arqueológico del territorio» Proyectos Intramurales Especiales del CSIC, ref. PIE2007 10I013. Investigador responsable: Victorino Mayoral Herrera; «Entre el Atlántico y el Mediterráneo: contraste de dinámicas en la evolución histórica del paisaje en el occidente peninsular a través de la Arqueología», HAR 2009-10666. Investigador responsable: Sebastián Celestino Pérez; «Paisaje, territorio y cambio social en el suroeste peninsular. De la protohistoria al mundo romano (Plan Nacional de I+D, ref. HAR 20081973). Investigador responsable: Victorino Mayoral Herrera.
} 


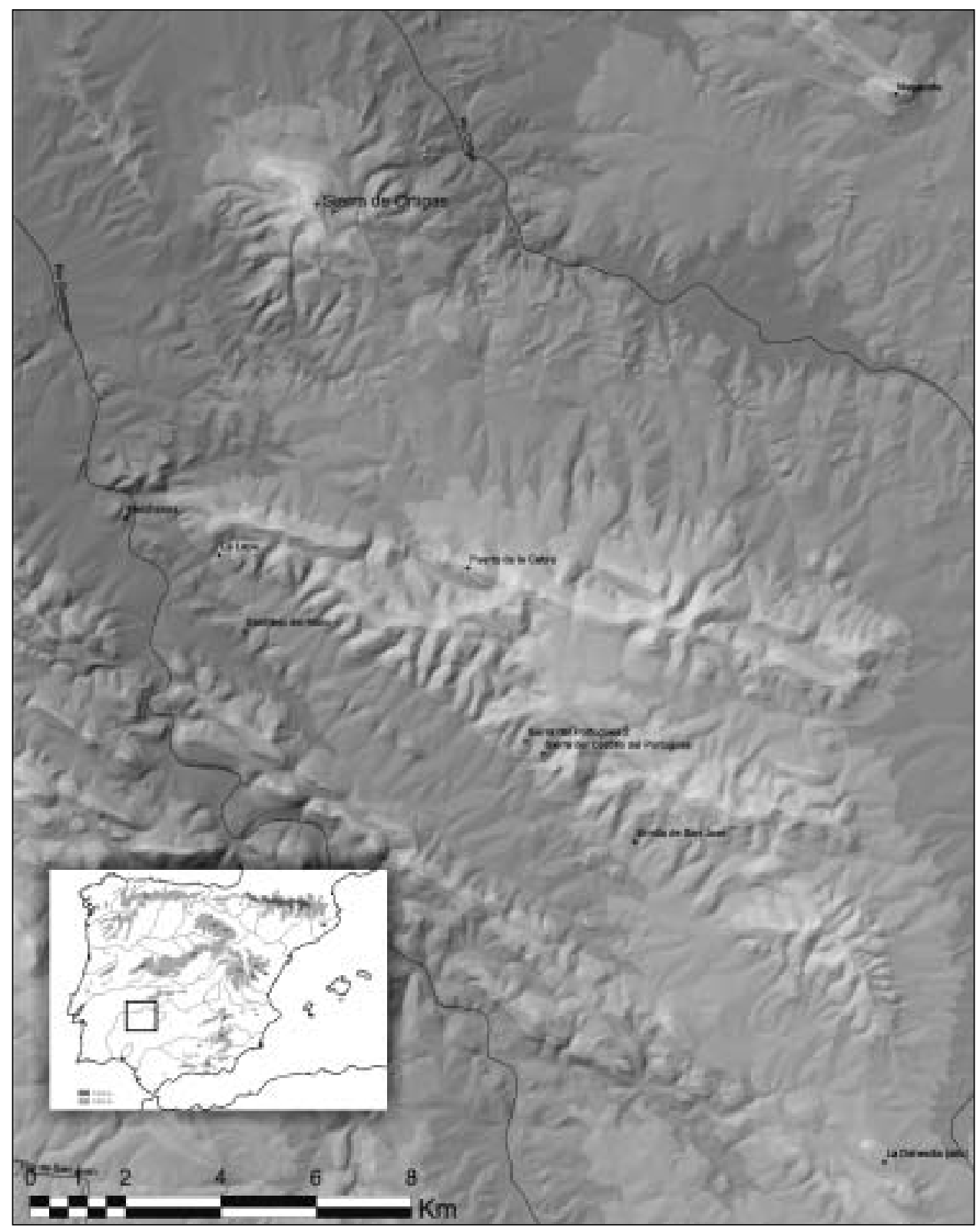

Figura 1. Localización del conjunto de sitios arqueológicos citados y delimitación del área de estudio dentro de la Península Ibérica.

por los trabajos de Ortiz y el propio Alonso, ya mencionados. En esta contribución el Castejón de las Merchanas es objeto de una breve descripción, y se presenta una planimetría por separado de los dos principales edificios. En cuanto a la adscripción cronológica del asentamiento, se considera imposible de determinar. Por su parte, el mismo Ortiz (Ortiz Romero 2006) se ha ocupado de una manera muy sucinta de mostrar los rasgos esenciales del conjunto de fortificaciones de altura de la sierra de las Pozatas, localizado en las inmediaciones de Castuera. En este trabajo dichos sitios son calificados como poblados, y se considera clara su vinculación con el proceso de conquista. No obstante no se formula de una manera clara cuál es la forma concreta en que las raíces del mundo indígena juegan un papel en su localización y naturaleza. Tampoco queda claro en qué medida y mediante qué procesos está presente el 
elemento militar, a menudo invocado al hablar de fortificaciones y recintos en La Serena.

Resumiendo, las fortificaciones de altura han constituido en el pasado un tema de investigación incipiente y prometedor, pero que no ha agotado aún todo su potencial como fuente de conocimiento, y que por tanto está lejos de ofrecer respuestas definitivas sobre su significado histórico. Pero para poder seguir avanzando, estimamos esencial señalar algunos de los aspectos en los que el trabajo precedente precisa ser desarrollado. En primer lugar, la gran abundancia de indicios superficiales hace que, intensificando el esfuerzo dedicado a cada sitio, sea posible obtener una documentación muy detallada y rica. En segundo lugar, las decisiones de localización de estos asentamientos han sido valoradas de un modo muy genérico. Finalmente, el debate sobre su significado histórico no puede avanzar sin la realización de excavaciones que contextualicen adecuadamente la construcción de estas fortificaciones y los materiales a ellas asociados. Al menos esta cuestión, tan elemental, sería precisa para construir una secuencia regional. Algo se ha avanzado ya en este sentido, con la excavación de enclaves de cronología republicana como Magacela (Ortiz Romero y Rodríguez Díaz 2004) o El Santo de Valdetorres (Heras Mora 2009).

\section{UN ESPACIO FRONTERIZO}

El río Guadamez es un afluente del Guadiana por su margen izquierda, y conecta las comarcas de La Serena y Vegas altas, en el este de la actual provincia de Badajoz. Esto convierte a dicho río en un corredor natural de acceso al valle del Guadiana desde el Guadalquivir, a través de la comarca cordobesa de Los Pedroches, y desde la Meseta sur pasando por la Siberia Extremeña. Dichos pasos son claramente definidos por las alineaciones predominantes de las sierras cuarcíticas, que segmentan el territorio en valles de diversa amplitud con una orientación predominante en sentido SE-NO. De manera global, esta estructura ha condicionado históricamente los ejes de comunicación, determinando el emplazamiento de asentamientos humanos en los puntos nodales de dicha red, como Metellinum, Magacela (posiblemente la mansio Contosolia), Lacimurga, Mirobriga o Artigi-Iulipa. En algunos puntos esta trama se dibuja con nitidez formando pasillos estrechos, cerrados por un frente continuo de crestas rocosas, como por ejemplo, entre las actuales poblaciones de Monterrubio de la Serena y Castuera, o entre Quintana de la Serena y Valdetorres, siguiendo en parte el citado curso del
Guadamez. En cambio en otros sectores, como a lo largo del curso del Ortigas, este tránsito se define por un vasto corredor formado por terrenos de suave orografía. Pese a la profunda tradición ganadera de estas tierras de dehesa, la amplia depresión que ocupan es también terreno favorable para una agricultura de secano. Tanto el registro paleobotánico como los numerosos indicios de tecnología agraria identificados en sitios arqueológicos, atestiguan el potencial productivo de la zona. El gran peñón fortificado de Magacela controla la aproximación al Guadiana desde esa dirección, dominando visualmente una vasta extensión. No obstante, esta red de comunicaciones permite la elección de una multiplicidad de rutas alternativas. Las propias sierras, como en el caso de La Lapa, son penetradas por caminos transversales, que ponen en comunicación valles secundarios a través de los cuales es igualmente posible la conexión entre ambas comarcas. Rodeadas de estériles paisajes rocosos, estas zonas de vaguada ofrecen un refugio para la actividad agrícola. Como argumentaremos más adelante, la existencia de estos «portillos» parece justificar la elección de algunas de las fortificaciones objeto del presente estudio.

\section{ALGO DE MÉTODO...}

Desde 2001, el Instituto de Arqueología desarrolla un programa de investigación centrado en la evolución del paisaje de La Serena a través de la Arqueología. Esta labor se ha ramificado, planteando el desarrollo de diversas líneas de investigación. Una de ellas está centrada en el estudio de las fortificaciones y recintos de la comarca, como parte de un análisis de los cambios provocados por la conquista romana en la organización territorial. En una primera fase de trabajo todos los sitios fueron visitados, obteniéndose una documentación detallada de su localización, estructuras (elaboración de croquis georeferenciados, descripciones, fotografía) y materiales (dibujo, descripción, clasificación). A medida que se ha ido completando esta información básica, la disponibilidad de nuevas herramientas de trabajo ha permitido incrementar la calidad de los datos.

En este sentido uno de los avances más significativos ha sido el empleo de un receptor GNNSS de doble frecuencia, capaz de obtener en tiempo real mediciones de precisión sub-centimétrica. La aplicación de este sistema es cada vez más frecuente en la arqueología peninsular (considérense trabajos pioneros como García Sanjuán 2004; García Sanjuán y Wheatley 2003), y práctica común desde hace tiem- 

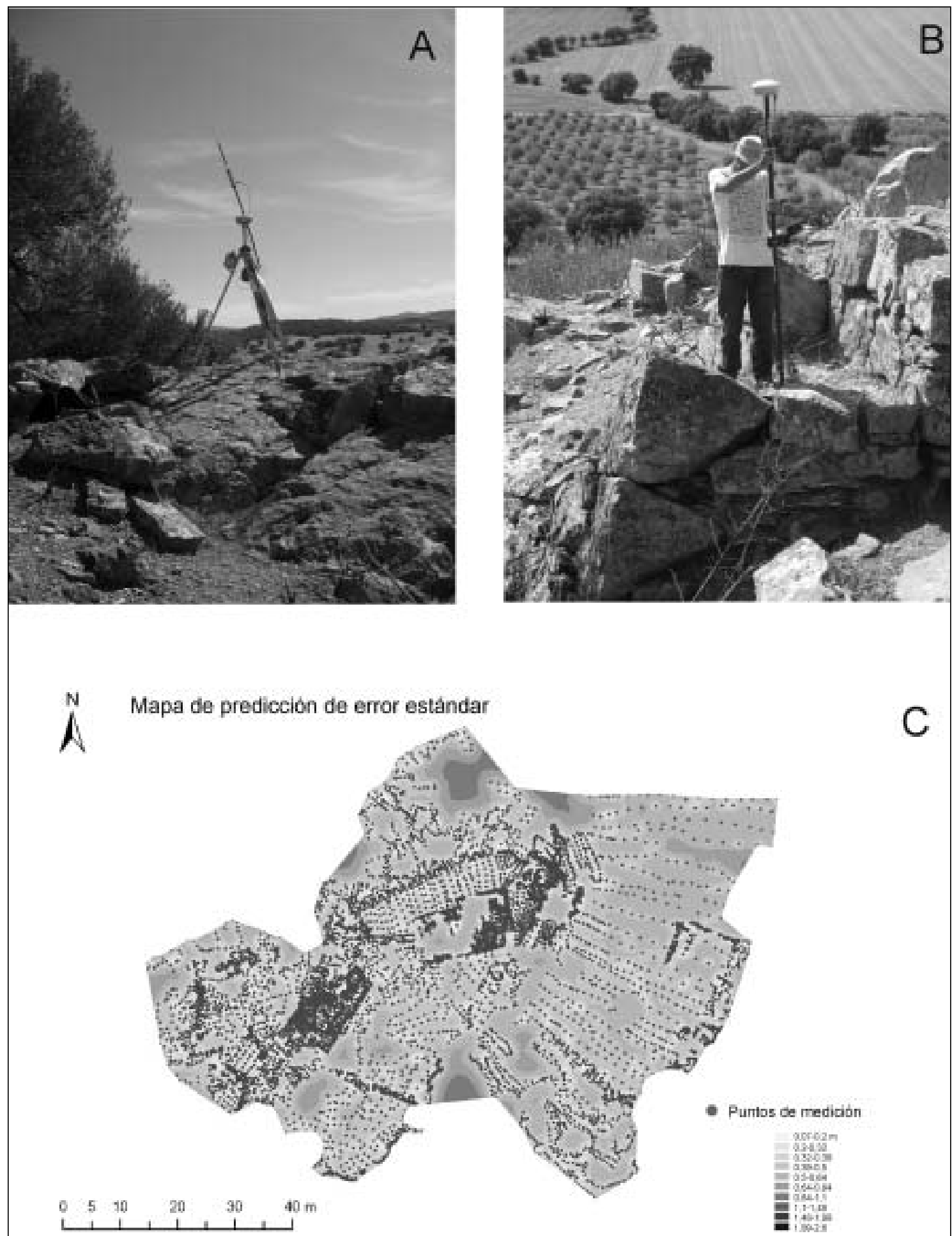

Figura 2. Proceso de trabajo para la generación del levantamiento topográfico de Las Merchanas. A.-Estableciendo una base para dar corrección en tiempo real al receptor móvil; B.-Ernesto Salas tomando mediciones sobre las estructuras; C.-Estimación del error en la superficie generada mediante kriging a partir de las mediciones. 
po en otros países (véase por ejemplo Ainsworth y Thomason 2003, Campana 2006). En otro trabajo se han expuesto los pormenores técnicos de nuestra experiencia particular (Martínez de Pozo et al. 2010), por lo que aquí realizaremos una exposición somera del proceso de trabajo. Lo que permite el dispositivo empleado es la captura de datos con suficiente precisión como para obtener, a partir de los mismos, un modelo digital de elevaciones de alta resolución, junto con una planimetría detallada. Esto no sólo puede ser útil para un análisis de las estructuras, sino que además permite identificar elementos soterrados perceptibles en superficie a través de pequeñas variaciones y anomalías en la altimetría. En nuestro caso la precisión del equipo empleado fue suficiente para el registro del tipo de variaciones presentes en la superficie. Por otra parte esta información es útil a la hora de modelizar y cuantificar aspectos relacionados con el asentamiento, tales como el comportamiento del material de superficie, o el funcionamiento de las estructuras defensivas.

El primer paso en este proceso es buscar el apoyo de puntos con coordenadas conocidas de gran precisión. El estacionamiento en los vértices de la Red Regente - gestionada por el Instituto Geográfico Nacional- (Barandillo Fernández y Quirós Donate 1996) proporciona la corrección diferencial necesaria para situar en el yacimiento una base de referencia fiable. En este caso contamos con un vértice geodésico a poco más de tres kilómetros al NE del sitio. En segundo lugar, a partir de esta referencia es posible tomar como origen de todas las mediciones un punto de coordenadas absolutas con un error en torno a un centímetro tanto en coordenadas horizontales como verticales. Utilizando un receptor móvil se realizó un levantamiento continuo en modo RTK (Real Time Kinematics) de todo el asentamiento. Esta técnica permite obtener corrección diferencial en tiempo real, agilizando notablemente el proceso de toma de datos. Por otro lado, se empleó un software diferente para la delineación de las estructuras visibles, generando polilíneas y polígonos 3D de todos los indicios. Finalmente, ambas fuentes de información se combinaron para generar un modelo tridimensional del sitio.

El paso principal de dicha tarea es la manipulación de la nube de puntos de cota generados (más de 7000) mediante técnicas de interpolación. Estas consisten básicamente en realizar estimaciones sobre un valor (la altura) a partir de un muestreo (las mediciones realizadas) para aquellas zonas para las que no poseemos dicha información. Por tanto no es una cuestión caprichosa la selección del método a utili- zar para generar estas superficies. La herramienta utilizada fue el módulo de análisis geoestadístico que posee Arcgis (versión 9.3). En este caso concreto optamos por la interpolación mediante kriging (un método geoestadístico ampliamente utilizado para la generación de modelos digitales de elevaciones), una vez constatado que el error cuadrático medio de las estimaciones de la altura era inferior al generado con otros procedimientos. Hay que señalar, en todo caso, que las particulares características del sitio condicionaron mucho la captura de datos, y que ello se ve reflejado en última instancia en la calidad global del modelo. Se trata de un emplazamiento con una topografía muy accidentada, con numerosos y escarpados farallones y paredes verticales de roca. Al mismo tiempo, la densa vegetación impide el acceso a muchas zonas. Por tanto, resulta muy irregular tanto la superficie del terreno como la distribución de las mediciones, generándose numerosos vacíos imposibles de cubrir incluso con otras técnicas topográficas complementarias, como el uso de estación total (disponíamos de una estación láser para el trabajo sin prisma que tampoco dio buen resultado en las zonas de vegetación más espesa).

\section{EL SITIO, UNA DESCRIPCIÓN}

Como bien supo ver en su día Suárez de Venegas, el Castejón de las Merchanas es el más grande y el más complejo de los conjuntos fortificados del valle del Guadamez. Sus casi 3.500 metros cuadrados de recinto se distribuyen a lo largo de las laderas y la cima de una pequeña elevación que domina una curva del río. Comenzando por lo más alto, el elemento más destacado es una estructura rectangular de $14,2 \times 8$ m (n..$^{-} 1$ en la figura 3 ), compuesta con grandes bloques de cuarcita (con dimensiones de hasta $230 \times 80 \mathrm{~cm}$ y entre 1,50 y 1,65 metros de grosor). Su aparejo es de doble paramento con un relleno interno de piedras pequeñas, fuertemente compactado con arcilla. En planta se definen bien sus límites, salvo por el lado oriental. Se distingue bien la interrupción del muro en su extremo $\mathrm{E}$, mientras que en la cara $\mathrm{S}$ se aprecia un pequeño quiebro y la prolongación de unos $60 \mathrm{~cm}$ hacia el $\mathrm{N}$ para dibujar un posible acceso.

El interior está colmatado de tierra y piedras, y muy alterado por excavaciones clandestinas, además de por la presencia de acebuches y encinas cuyas raíces cubren las estructuras. Sin embargo, se diferencian bien dos muretes de aparejo más menudo y orientación SO-NE. El más meridional (Fig. 5, identificado 


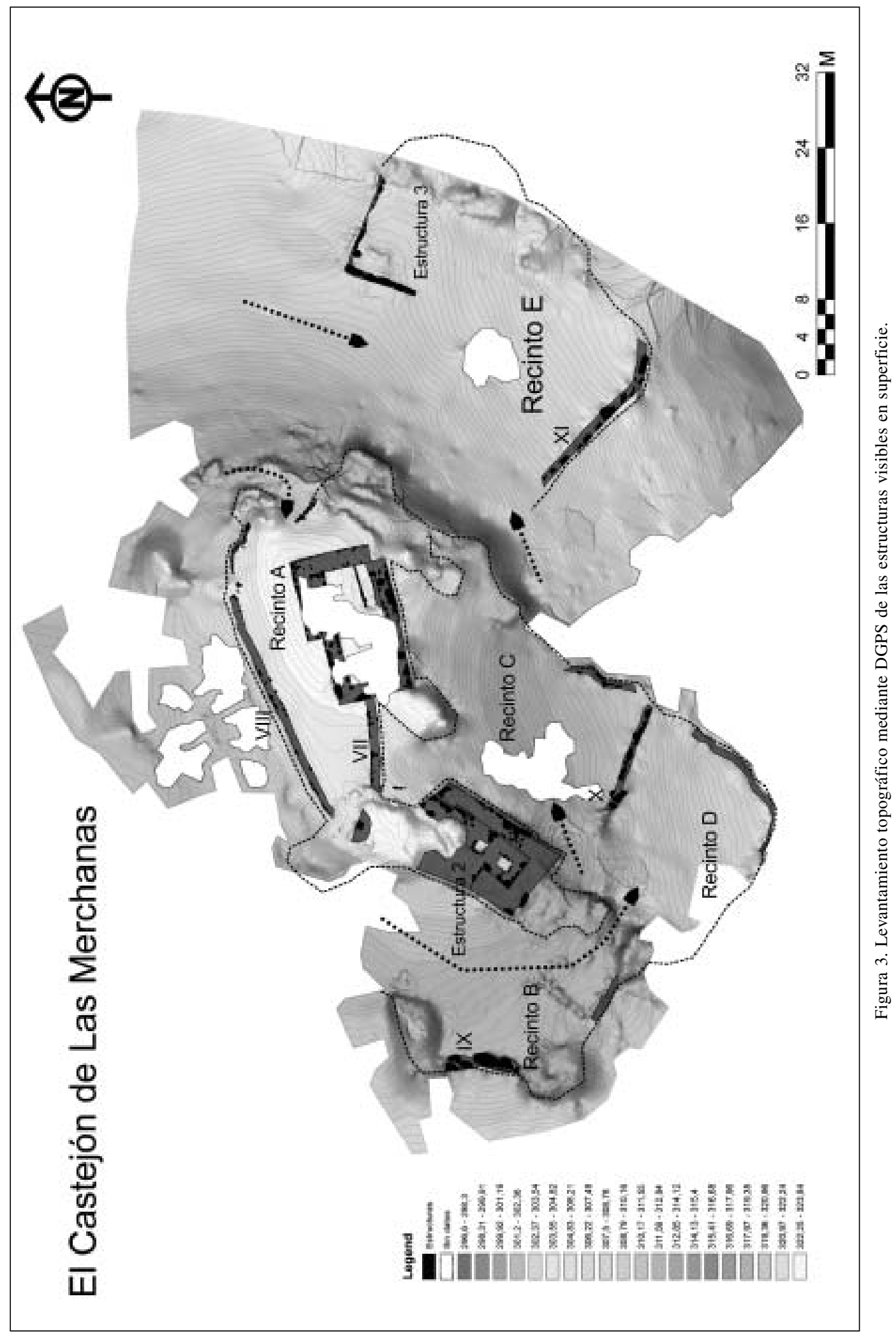


con un IV) tiene unos $50 \mathrm{~cm}$ de anchura y se adosa a las esquina SE del gran muro de cierre (Fig. 5, identificado con un V). Del segundo, situado al $\mathrm{N}$ y en paralelo con el anterior, sólo conocemos en cambio la cara exterior. La corta distancia entre ambos (apenas un metro) plantea dudas sobre si funcionaron delimitando un espacio de hábitat o si únicamente sirven de apoyo para una estructura superior. Lo que parece claro en todo caso es que el murete situado al $\mathrm{N}$ se adosa a un muro de unos dos metros de grosor (Fig. 5, identificado con un IV), que cierra la estructura 1 por el lado $\mathrm{E}$ y abraza todo el costado $\mathrm{N}$ del paramento de grandes bloques. La técnica empleada para su construcción consiste en delimitar el perímetro con bloques de cuarcita de tamaño medio, para luego rellenar el interior de piedras más menudas.

En torno a este conjunto de estructuras se define un perímetro amurallado que cierra la parte más alta del cerro (recinto A en la Figura 3). Todo el lado sur queda defendido por el cierre de la propia estructura 1 , que apoya directamente sobre los afloramientos rocosos. Estos últimos demarcan una muralla natural cuyos huecos son cubiertos por lienzos de mampostería de cuarcita. Por el oeste, un tramo de muro de 1 metro de grosor (Fig. 3, identificado con un VII) conecta la estructura 1 con el farallón en el que se asienta la segunda construcción de la cima (estructura 2 de la figura 3). Aunque dicho muro está completamente arrasado, se distingue claramente cómo cerraría el acceso por el $\mathrm{SO}$ el recinto A. A lo largo de la cara $\mathrm{N}$ se conserva bien el trazado de un muro en aterrazamiento de unos $80 \mathrm{~cm}$ de anchura y más de 30 metros de longitud (Fig. 3, identificado con un VIII). Finalmente, en el costado oriental se distingue también un pequeño tramo de muro apoyando en los farallones rocosos. Algunos metros más abajo, un recorte artificial de la roca dibuja una pequeña rampa que facilita la conexión con la plataforma inferior. En su extremo aflora lo que parece una superficie escalonada formada por lajas de pizarra. Posiblemente se corresponden con un pasillo de comunicación entre los dos sectores del recinto. En total, este reducto de la cima encierra una superficie de cerca de 300 metros cuadrados, si incluimos el espacio interior de la estructura rectangular.

Como ya se ha indicado, al SE de este conjunto y apoyando en otro crestón rocoso, destaca otra estructura bastante compleja y monumental ( 2 en la Figura 3, Figura 4). Su núcleo es un bastión de una longitud y anchuras máximas de $12 \times 7 \mathrm{~m}$. El aparejo es de grandes bloques de cuarcita apenas sin desbastar, y el interior está compuesto de un macizado de piedras que rellena los huecos entre la roca hasta formar una superficie nivelada. El proceso de derrumbe de este relleno permite reconocer las sucesivas tongadas de piedras. No obstante se diferencian dos huecos cuadrangulares de 1,2 metros de lado alineados en el interior de la estructura. Demasiado pequeños para conformar habitaciones, los espacios que definen parecen corresponder más bien a subestructuras del alzado del bastión. Rodeando a este último por todos sus lados, se adosa otra estructura delimitada de nuevo por grandes bloques de cuarcita y relleno de piedras al interior. Tiene una anchura de entre 1,8 y 2, 6 metros, y en su frente sudoccidental presenta un gran paramento ataludado con más de dos metros de alzado conservado. Parece tratarse de un refuerzo para la sustentación del bastión.

Por debajo del conjunto de la cima formado por las estructuras 1 y 2 y el recinto $\mathrm{A}$, se distinguen cuatro zonas bien diferenciadas del asentamiento. Al $\mathrm{O}$ y NO del bastión, dos tramos de muro de gran aparejo que se apoyan en los afloramientos rocosos (Fig. 3, identificado con un IX; Fig. 6, 5) definen un ámbito de unos 325 metros cuadrados (recinto B). La técnica de construcción es muy tosca, con enormes bloques de cuarcita sin ningún tipo de labra. Algunos, de 2,6 por $1,5 \mathrm{~m}$, parecen simplemente haber sido extraídos in situ y empujados hasta formar el frente de la muralla. Esta combinación de peñas y muros parece encauzar el acceso a la parte superior del conjunto, obligando a realizar un recorrido en recodo dejando el bastión a la izquierda. Lo que no queda claro es a partir de éste cómo se solucionaría la entrada. Un estrecho corredor entre dos farallones resulta ser la única opción para penetrar en el interior. Dicho pasillo da acceso a otro recinto delimitado por la combinación de los afloramientos y un muro en terraza de gran aparejo. Es el recinto $\mathrm{C}$, que con sus 600 metros cuadrados, queda delimitado al $\mathrm{N}$ por la estructura 1 , los afloramientos en los que apoya, y por el muro que enlaza a ésta con el bastión. Todo el lado oriental se cierra de manera natural por el cortado de la roca, mientras que al $\mathrm{O}$ el gran talud del refuerzo del bastión marca el límite. En cuanto al muro de grandes bloques que demarca el aterrazamiento, (Fig. 3, identificado con un X) no llega a enlazar con el farallón en el que se abre el paso ya mencionado. En este punto se da acceso a otro recinto (D en la figura 3), de unos 250 metros cuadrados. Su perímetro queda definido de nuevo por la alternancia de roca y paramentos de grandes bloques, aunque no se distinguen como en el anterior alineaciones de muros in situ.

Aún existe un quinto recinto dentro de este asentamiento (E): se localiza en el extremo sureste del 


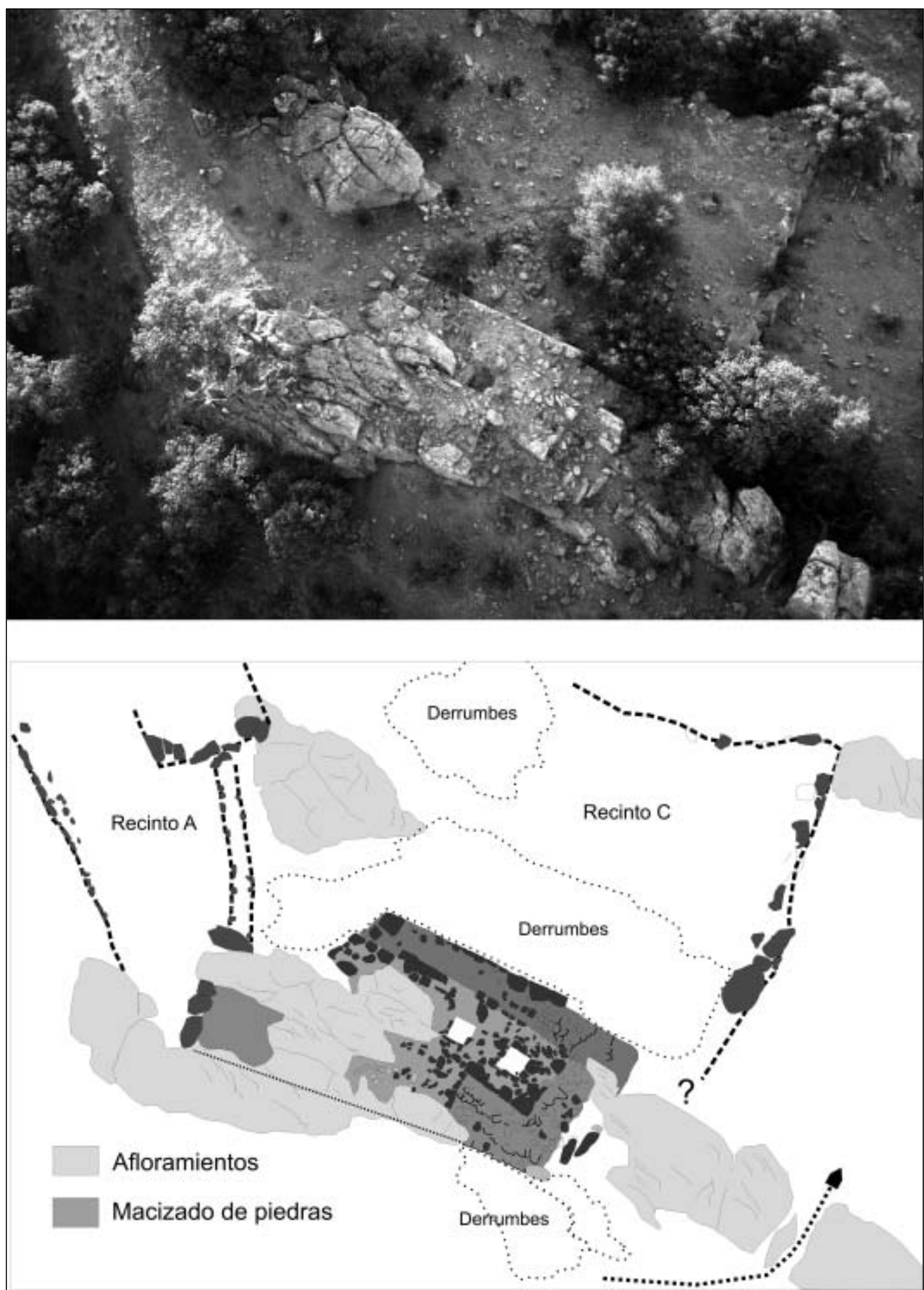

Figura 4. Fotografía aérea vertical de la estructura 2. Debajo, croquis interpretativo. Fotografía: Victorino Mayoral. 
cerro, y queda delimitado hacia el E por un gran cortado vertical de roca. El frente suroeste se cierra por un aterrazamiento formado por un muro de grandes bloques (Fig. 3, identificado con un XI). Éste no llega a conectar con la pared de roca que forma el límite S y SE del recinto de la cima. No queda claro por las estructuras visibles en superficie si esta falta de muro obedece a la presencia de un acceso. Respecto al límite $\mathrm{N}$ de este sector, no queda bien definido. No se reconocen aterrazamientos, ni restos de posibles muros de cierre por ese lado. La topografía ofrece una suave ladera que parece dejar completamente abierto ese frente. Únicamente marca una discontinuidad la presencia, en el extremo NE del recinto, de una estructura cuadrangular de unos $8 \times 10$ metros que se apoya en la roca para definir su cierre oriental (número 3 en la Figura 3). Los muros son de factura tosca, con una única hilada visible de grandes lastras, de hasta 2,7 metros de longitud y un grosor medio de 70 a $80 \mathrm{~cm}$. La envergadura del aparejo recuerda a la de la estructura de la cima.

Si seguimos rodeando el cerro por la falda oriental, no encontramos ya líneas de aterrazamiento que delimiten el asentamiento. En cambio, un largo crestón rocoso define por este lado una potente barrera que constriñe el acceso a toda la ladera oriental del cerro. Entre éste y las estructuras de la cima, se aprecia en la topografía una depresión alargada, en parte definida por un recorte en la roca, y que coincide con la conexión entre el cerro fortificado y la loma inmediata, justo frente al tramo de muralla que cierra el recinto por el norte. Es una zona actualmente ocupada por una vegetación muy densa, por lo que ha resultado muy complicado tomar datos sobre la altimetría. Esta vaguada se cierra a la altura de una rampa que permite ascender hacia el bastión por el acceso en recodo ya descrito.

\section{APAREJOS, TÉCNICA CONSTRUCTIVA}

Los diferentes elementos de este sistema defensivo muestran la aplicación de diversas soluciones en cuanto a las técnicas de construcción empleadas. Comenzando por las estructuras de la cima, el edificio situado al $\mathrm{N}$ del recinto fue construido con un aparejo de grandes dimensiones a base de bloques poligonales, calzados con ripios. En algún caso se aprecian gruesas lajas para nivelar el alzado de los muros. Algunos bloques alcanzan una longitud de hasta 2,5 metros. Son muros de doble paramento, aunque el espacio del núcleo es muy reducido y no se recurre a un relleno interno de piedras pequeñas com- pactado con arcilla rojiza. Planteamos que esta fábrica tan robusta actuaría como un zócalo para un alzado de tierra, tal y como sugieren los restos que aparecen revueltos en el interior del edificio.

En cambio, el paramento que se adosa a esta estructura por el $\mathrm{N}$ y el $\mathrm{E}$ es de un aparejo mucho más ligero, formado por una alineación exterior de bloques pequeños con un careado no muy cuidado, y un relleno interior de piedras pequeñas. Este contraste y la relación constructiva entre ambos elementos nos sugieren la posibilidad de que se trate de la base de una plataforma para un acceso elevado. Refuerza esta idea la presencia de los dos muretes paralelos con apenas un metro de separación, que se adosan a los muros que delimitan el edificio y cuya cresta coincide en cota con ellos. Estos parecen definir la base de una superficie de uso sobreelevada. En todos los casos en los que se ha podido examinar el remate de estos muros, la horizontalidad de la hilada superior indica con claridad la existencia de alzados de tierra. De hecho, en torno a la estructura 1 se identificaron algunos fragmentos de adobes. Por lo que respecta al sistema de cubiertas de este edificio, hay que hacer notar la ausencia de material latericio romano, que en general es sumamente escaso y muy rodado en todo el asentamiento. Sí son abundantes en cambio las lajas de pizarra, a veces de gran tamaño (como ya se ha dicho son empleadas como material en la construcción de la rampa de acceso al recinto A). Planteamos aquí la hipótesis de que puedan también haber sido empleadas para los techados.

En cuanto al bastión, destaca sobre todo por lo masivo de las fábricas empleadas. El refuerzo exterior en talud emplea grandes bloques de cuarcita sin apenas desbastar. La estructura interior presenta en cambio una técnica más cuidada, con una alineación mucho más regular, intercalando lajas de nivelación y con el refuerzo de grandes bloques bien escuadrados en las esquinas. También es indicador de una gran regularidad la alineación y dimensiones de los espacios cuadrangulares.

Finalmente, los muros de aterrazamiento que definen los recintos inferiores están compuestos por grandes bloques poligonales apenas sin trabajar, encajados en la ladera, a veces con grandes calzos, algunos tan voluminosos que sugieren una extracción directa en el lugar en el que son emplazados.

Hay por tanto un ajuste bastante funcional entre la envergadura y cuidado de la técnica edilicia y la funcionalidad de los elementos que componen el complejo arquitectónico. En cuanto a la secuencia temporal de su creación, se identifican con claridad algunas fases, aunque se corresponden con pocas 

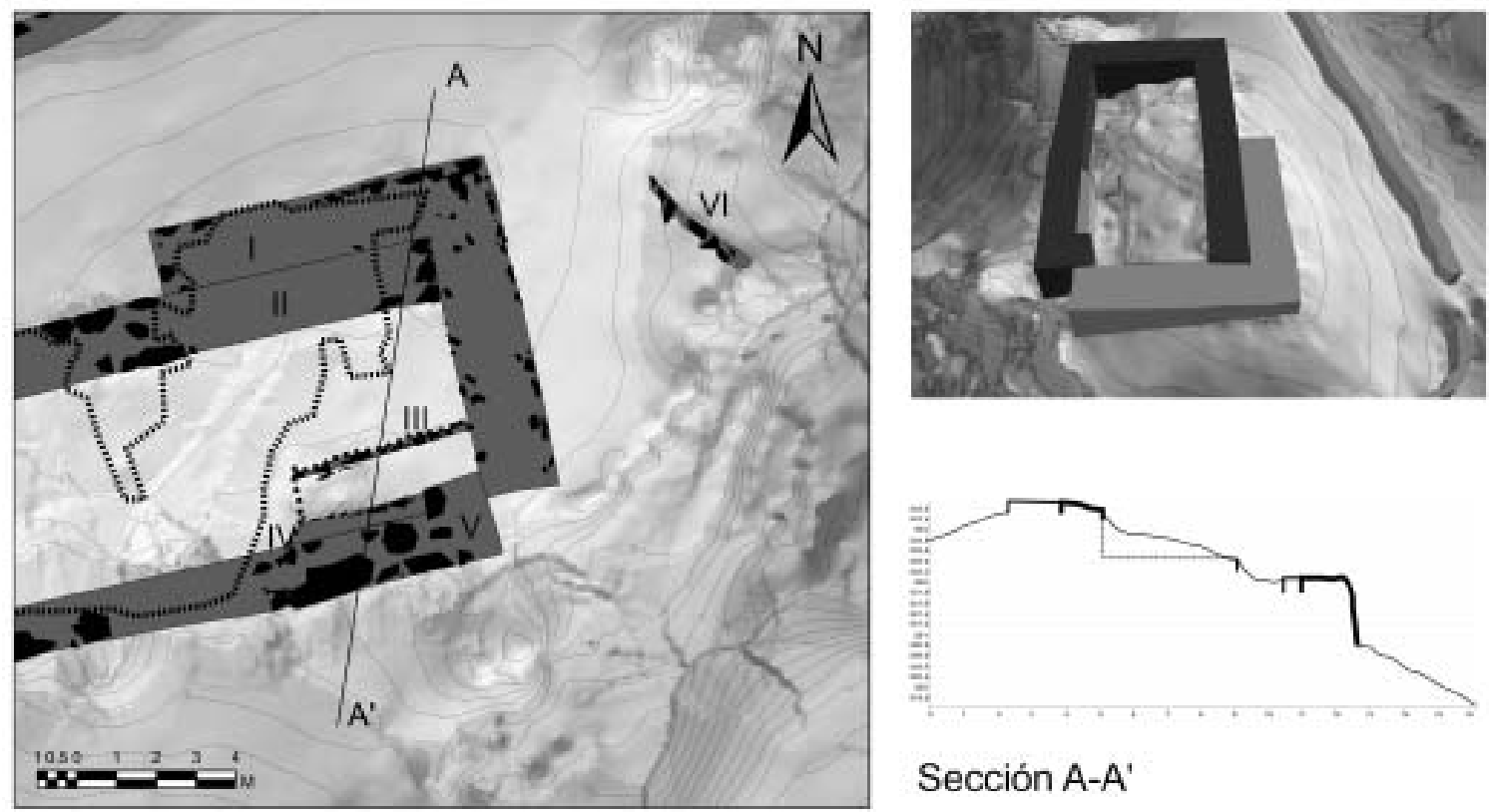

\section{Sección A-A'}

Figura 5. Estructura 1: Planta, sección y restitución de volúmenes. Los números romanos indican las referencias a los muros descritos en el texto.

dudas al proceso de construcción. No nos parece que las fábricas empleadas ni sus relaciones muestren diferencias acusadas, que pudieran ser indicativas de reformas o replanteamientos del sistema a través del tiempo (quizás como único ejemplo el posible tapiado del acceso oriental del recinto A). Parece tratarse de un proyecto unitario de fortificación del cerro, que demuestra una gran capacidad técnica y de aprove-
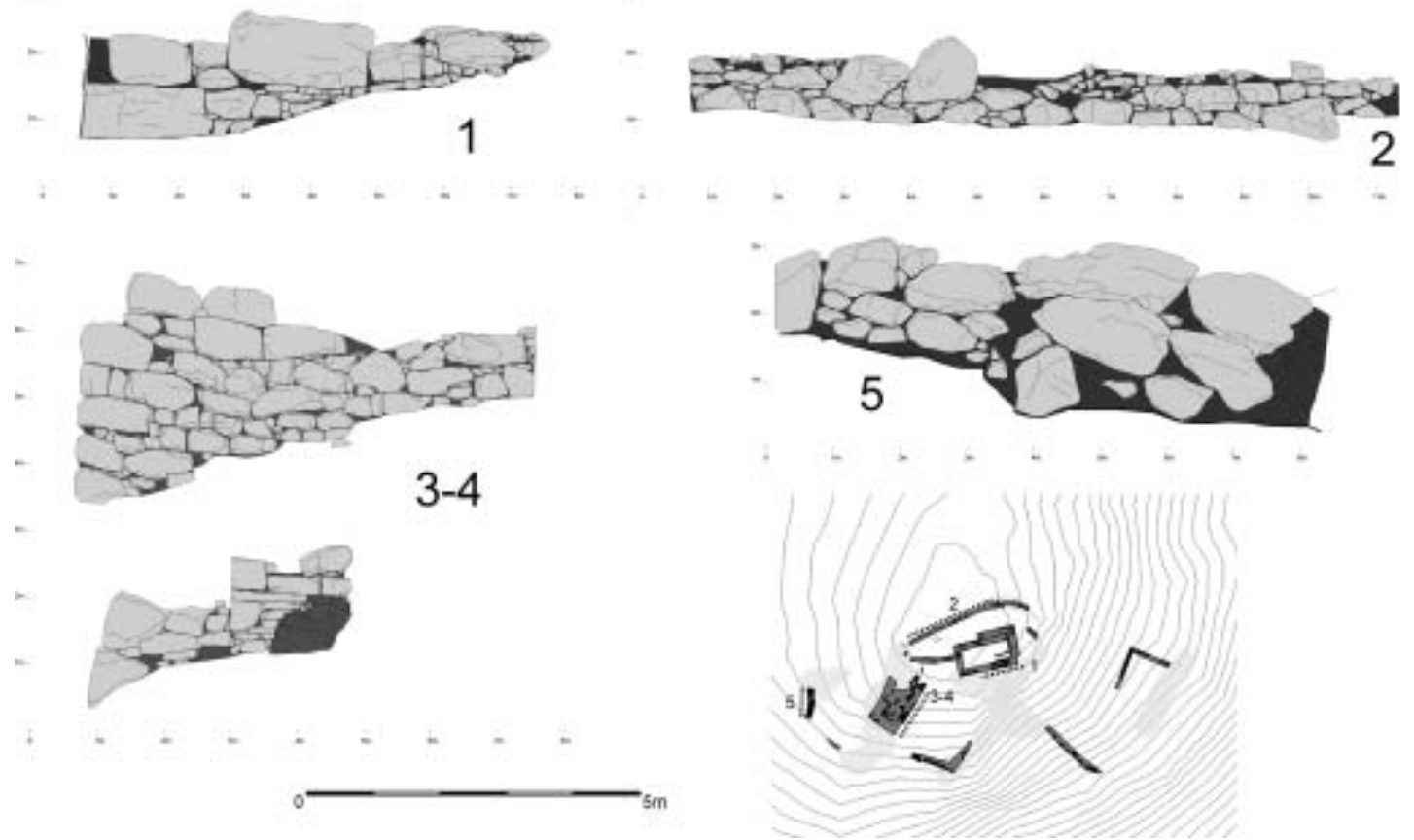

Figura 6. Alzados de los paramentos de diversos sectores del asentamiento. 
chamiento de la morfología de su emplazamiento. Como veremos más adelante estos son rasgos que caracterizan al resto de los asentamientos analizados en este trabajo.

\section{7. ¿UN SISTEMA DEFENSIVO EFICIENTE?}

El volumen de las estructuras de las Merchanas, y su localización en un emplazamiento tan escarpado junto al río Guadamez, sugieren con fuerza la idea de que la capacidad de defensa y el control del entorno fueron preocupaciones dominantes para su construcción. Lo que los restos observables permiten plantear es que, en primer lugar, contamos en la cima con un perímetro murado bastante reducido. En casi todo su contorno grandes paredes verticales de roca refuerzan o sustituyen a los lienzos de mampostería. La topografía es más suave únicamente por el costado que conecta con el cerro situado al N. En esta zona se aprecia una vaguada que parece coincidir con el muro de cierre del recinto, y que podría corresponderse con un foso. Desafortunadamente es difícil contrastar este extremo, ya que, como hemos indicado, la tupida vegetación impedía apreciar con claridad el terreno y aún menos tomar datos. El único punto de acceso identificable del recinto superior se localiza en su extremo oriental. Se trata, como ya hemos indicado, de una estrecha rampa, seguramente recortada en la roca del sustrato, que conecta con el recinto $\mathrm{E}$ a través del espacio entre un afloramiento y un tramo de muro. Este último ofrece un hueco de poco más de un metro de anchura, por lo que cabe la posibilidad de que en realidad estuviera sellando un acceso inicialmente expedito. Otra posibilidad es que el lienzo que enlaza los dos farallones, al SO del recinto, tuviera un vano que no se ha conservado debido a la intensa erosión es ese punto.

En cualquier caso dicho muro define una separación con el farallón sobre el que se asienta el bastión. Éste aparece de hecho como un elemento que da continuidad al cierre del recinto por el norte, y actúa como divisoria entre la parte más alta del asentamiento y el resto. A su izquierda controla directamente la aproximación a través del recinto $\mathrm{B}$, y es justamente frente a él donde se localiza el único pasillo de conexión con los recintos C y D entre los grandes afloramientos rocosos. Estos dos últimos no ofrecen dudas respecto a su cierre, y ambos son fácilmente defendibles por su costado $\mathrm{S}$ y $\mathrm{E}$ gracias al fuerte desnivel marcado por la presencia de afloramientos. Por último, la descripción ya realizada deja claro que el recinto E cuenta con la defensa natural de los riscos rocosos por el $\mathrm{E}$ y de un muro de gran aparejo por el SO, pero queda completamente abierto hacia el N. Esto explicaría la presencia de la estructura 3 , justo en el punto en que se estrecha el acceso al recinto.

\section{LOS MATERIALES ARQUEOLÓGICOS}

La intensa erosión de la cima y las laderas del cerro ha alterado seriamente una buena parte de los depósitos arqueológicos. A ello se une la activa presencia de expoliadores, ya que se trata de un enclave relativamente accesible. Todo ello ha dado lugar a una importante presencia de fragmentos cerámicos en superficie. El material cuyo estudio de presenta aquí es resultado de una recogida selectiva realizada durante el desarrollo de los trabajos de documentación. Todos estos factores generan una visión sesgada de las facies cronológicas del sitio. Esperemos que en un futuro, con nuevas actuaciones en el lugar, podamos plantear un estudio contextual del mismo que nos aporte una visión histórica más concreta.

El análisis del material nos permite obtener datos vinculados a la cronología y funcionalidad del sitio. Podemos advertir que nos encontramos en primer lugar con una cultura cerámica de cuño netamente indígena, no sólo en las formas sino también en las cocciones, tipos de pasta y acabados, con cerámicas que podemos perfectamente insertar en cronología de la Edad del Hierro. Al igual que venimos indicando para otros contextos de la Serena, estas se caracterizan por estar a medio camino entre las tradiciones indígenas y la cultura material romana propiamente dicha. Así, en estos contextos conviven tanto urnas truncadas y decoradas a bandas pintadas con ánforas o ungüentarios fusiformes de conformación típica tardorrepublicana.

Genéricamente las cerámicas analizadas presentan una gran homogeneidad compositiva, que se traduce en tres grupos de pastas cerámicas. Un primer grupo de pastas muy gruesas, toscas, con coloración virada del rojo oscuro al marrón y grandes desgrasantes de granulometría media-gruesa (sobre todo cuarcitas y feldespatos). Este grupo sería el propio de los recipientes de almacenaje y cocina. Un segundo grupo, muy similar al anterior pero una mayor finura en su composición, engloba a los recipientes comunes y de mesa. Un tercer grupo se caracteriza por pastas muy depuradas, de coloración grisácea virando a asalmonada muy amasada y fina, y con un acabado muy pulido, sobre todo para urnas y otras categorías de factura fina y depurada. Estos tres conjuntos pue- 


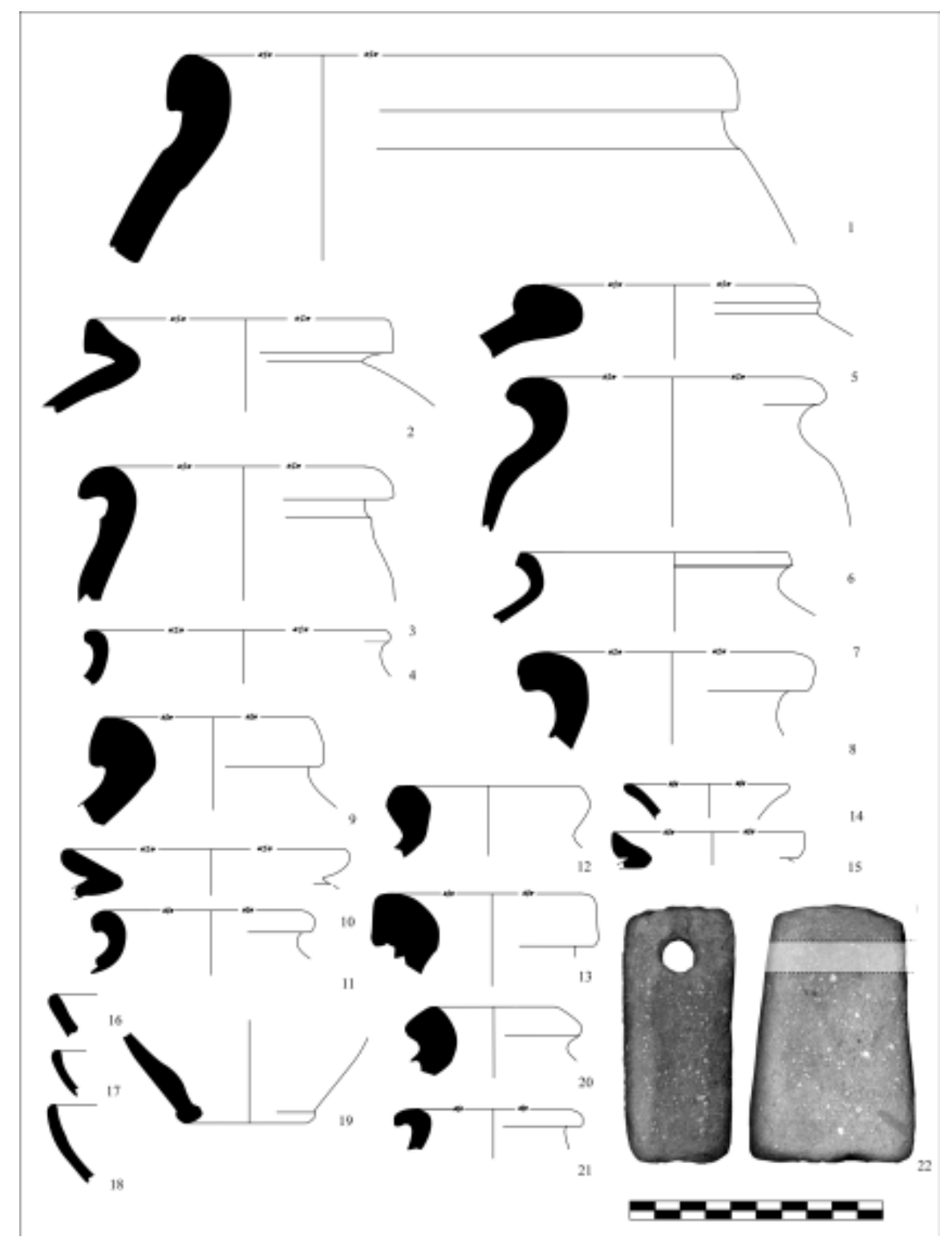

Figura 7. Material cerámico de superficie del Castejón de las Merchanas.

den ser calificados como de origen local-regional al presentar unas características compositivas muy similares a las de épocas posteriores.

En cuanto a las formas, dentro de estas producciones predominan, grosso modo, los recipientes destinados al almacenaje, lo que nos daría un primer indicio de una economía de autoconsumo y excedentes en el entorno. Esto vendría apoyado por la aparición de un solo galbo anfórico de factura muy pulverulenta y coloración amarillenta-verdusca, que nos daría una procedencia focalizada en el Círculo del Estrecho.
Recordemos que ánforas de esta procedencia se han localizado en contextos tardorrepublicanos de carácter militar, caso del ya citado sitio de Valdetorres con una cronología clara del II a. C., con ánforas del tipo T. 9.1.1.1. (Heras y Bustamante, 2007).

La morfología de estos recipientes de almacenaje se centra sobre todo en bordes cuadrangulares, «a gancho» (Fig. 7, n. ${ }^{\text {s }} 3,4,6$ y 11), otros que evocan a los tipos protohistóricos de «pico de ánade» (Fig. 7, n.․13) (ver Hernández et al. 1989, Fig. 42, n. 354356 o Fig. 51, n. 456-464), redondeados (Fig. 7, n..$^{\circ}$ 

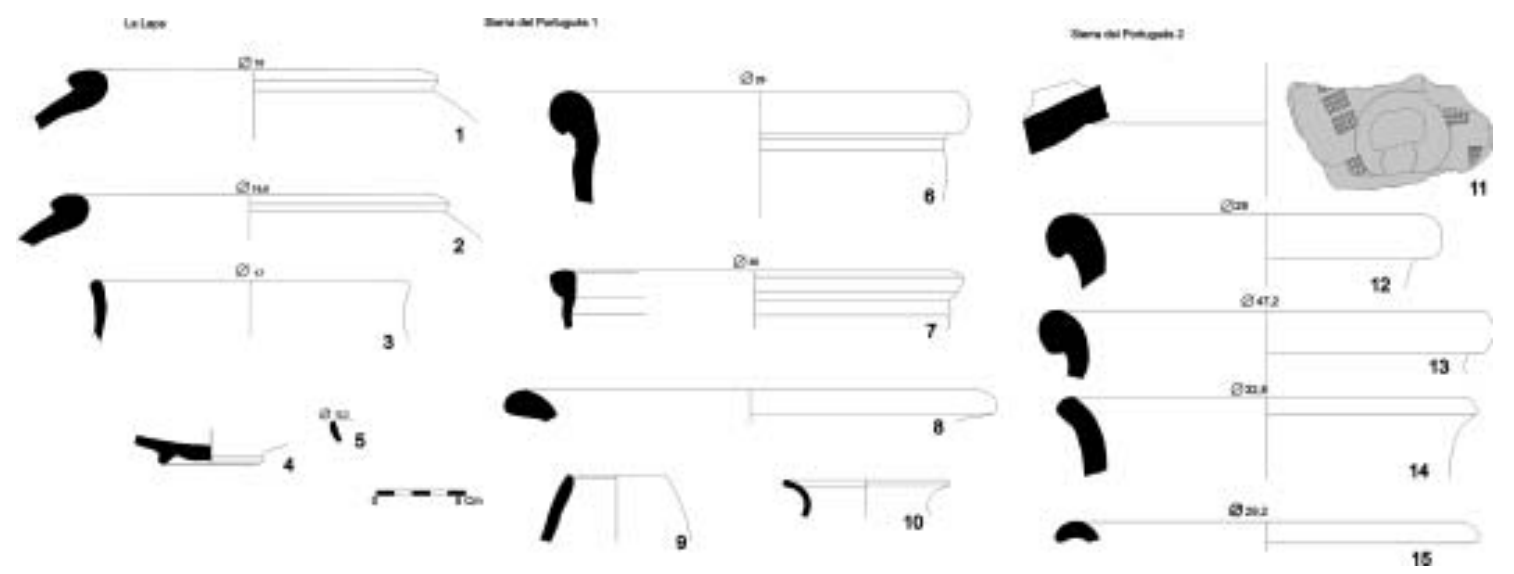

Figura 8. Selección de material de superficie de las fortificaciones de Castillo del Portugués 1 y 2 y La Lapa.

12), rectangulares (Fig. 7, n.․ 8), triangulares (Fig. 7, n. 1,9 y 20) y un grupo exvasado (Fig. 7, n.․ 7). Los fondos se presentan totalmente planos o indicados (Fig. 7, n.o 19). En este grupo destacamos una gran orza biansada con morfología «a saco», similar morfológicamente hablando a algunas documentadas en la Baeturia en el tránsito del II-I a.C. (Berrocal 1998, fig. 26, n. 9). También aparecen tipos de clara inspiración romana, como los dolia (Fig. 7, n.. 5), que de nuevo nos da indicios de la convivencia de tradiciones indígenas con las romanas.

De igual modo, aparecen ollas destinadas al procesado de alimentos con morfología variada, bien de borde vuelto (Fig. 7, n.․․ 21), levemente exvasado, engrosado, de borde truncado así como un tipo que imita claramente a los recipientes Vegas 2 (Fig. 7, n. 3, 10 y 15). Los fondos localizados pueden ser bien planos o marcados. También dentro de la cadena de preparado y servido de alimentos destacamos un pico vertedor, así como asas que formarían parte de recipientes de gran grosor.

Ya para el servicio directo aparecen los cuencos de borde engrosado (Fig. 7, n.․ 16), exvasado (Fig. 7, n.o 17) o ligeramente entrante (Fig. 7, n.. 18). También se localizan pequeñas orzas de funcionalidad indeterminada. Las urnas también aparecen con unas pastas muy depuradas y con borde vuelto al exterior (Fig. 7, n. 14), así como truncado. Es interesante ver las semejanzas existentes entre las urnas aquí propuestas y las desarrolladas por los túrdulos en la Beturia (Berrocal, 1998, Fig. 29).

Frente al grueso de las producciones locales destacamos algunos fragmentos de importados que nos pueden acercar en cierto modo a la cronología del contexto. En primer lugar destacamos como indica- dor más antiguo la presencia de un fragmento de un ungüentario fusiforme del tipo Oberaden 28/Cami1li B11-12, con resto de pigmento rojizo en su tercio superior, de posible procedencia itálica, muy común en el tránsito del II-I a.C. (Camilli 1999, $32-33)^{2}$. Recordemos que estos ungüentarios, aunque en evolución con cuerpos a modo de redoma (Cami1li 23), aparecen muy comúnmente en los contextos de la primera edad julio-claudia en Mérida. En segundo lugar se localizaron dos pequeños fragmentos de terra sigillata, una itálica aretina y otra hispánica. La producción de sigillata itálica de procedencia aretina inicia su andadura en torno a la mitad del i a.C., siendo su momento de auge la época augustea. Por el contrario, la sigillata hispánica inicia su distribución en territorio lusitano en época Flavia. Por consiguiente, aunque de manera muy limitada, podemos observar representados en Merchanas al menos dos momentos de la época altoimperial. Como ocurre en otros casos que a continuación expondremos, no queda claro por el momento la entidad de esta última ocupación (¿explotación agrícola, asentamiento tipo aldeano?), ni la continuidad respecto a la fase anterior. En la siguiente sección realizaremos una valoración conjunta del valor de estos indicadores cronológicos, a la luz de los materiales detectados en los restantes sitios analizados en este estudio.

\footnotetext{
${ }^{2}$ Esta pieza fue localizada en las tareas de excavación que se iniciaron en el sitio cuando el presente texto estaba ya cerrado para su presentación. Aunque los resultados de estos trabajos serán cumplidamente publicados en el futuro, nos pareció un elemento significativo de cara a la posible existencia de una ocupación tardorrepublicana en este asentamiento.
} 


\section{EL CASTEJÓN DE LAS MERCHANAS EN EL CONTEXTO DE LAS FORTIFICACIONES DE ALTURA DE LA SERENA}

\subsection{LOS SITIOS, BREVE DESCRIPCIÓN}

Como se dijo en el inicio de este trabajo, Las Merchanas es solo un caso dentro de un amplio conjunto de fortificaciones de altura que se concentra en las áreas de paso que dan acceso a la comarca de $\mathrm{La}$ Serena. Actualmente disponemos de un creciente volumen de información que nos permite realizar algunas consideraciones sobre los criterios de localización, estructura y técnicas constructivas de un amplio número de sitios. En este trabajo se analiza sobre todo el grupo localizado a lo largo del eje formado por el río Guadamez, aunque también se valoran datos referentes a las fortificaciones de altura que se sitúan a lo largo de las sierras de los Argallanes, en Zalamea, y en las de Castuera y Benquerencia de la Serena.

La Dehesilla (Fig. 9, n.o 6, Fig. 10, n. )

\section{Localización}

El recinto de La Dehesilla se localiza en la cima de la sierra del mismo nombre, en el término municipal de Zalamea de la Serena. Se trata de una sierra que presenta un máximo de 578 metros de altitud. Está formada por dos grandes crestas de cuarcitas armoricanas. La situada más al norte es la más escarpada, y domina directamente el paso de la Cañada Real Leonesa, que viene desde el sur, además del puerto que conecta Valle de la Serena con Quintana. En esta zona no se han localizado restos arqueológicos. En cambio, el afloramiento más meridional proporciona una superficie más adecuada para servir de apoyo a la fortificación. Desde él se domina igualmente el paso de la cañada. El control visual desde la cima es amplísimo, abarcando sobre todo las extensas zonas bajas de Valle, Quintana, Higuera y Zalamea de la Serena.

Las estructuras que actualmente se pueden identificar se distribuyen a lo largo de la cresta cuarcítica, aprovechando al máximo la accidentada orografía para crear una serie de siete plataformas delimitadas por muros que se encajan en la roca formando aterrazamientos. El aparejo es de mampostería a hueso, a base de grandes bloques de cuarcita con calzos y cuñas realizados con pequeñas lajas. La longitud total de este conjunto es de unos 130 metros, con una anchura máxima de unos 15 metros. En total la superficie habitable de la fortificación es de cerca de 1200 metros cuadrados. Este cálculo incluye una plataforma situada en la ladera sur occidental, inmediatamente por debajo de las murallas del recinto de la cima.

En cuanto al diseño de la construcción, como ya se ha dicho prima completamente el criterio de máxima adaptación a las posibilidades que ofrece la roca. El acceso original podría realizarse desde el costado noroccidental. En su extremo norte se distingue un muro en barrera que haría frente al estrechamiento que conecta con la elevación contigua de la sierra. Un gran bloque careado hacia el interior del muro sugiere la existencia de otro acceso por este lado. En el extremo opuesto en cambio se aprecia con claridad que el frente de muralla cierra por completo el lado sur. En torno a las estructuras se aprecian numerosos indicios de la existencia de mineralizaciones de hierro.

\section{Materiales arqueológicos}

La densa vegetación y lo escarpado del terreno impidieron reconocer apenas algunos fragmentos atípicos de grandes contenedores de factura tosca y piezas muy rodadas de cerámica común de pastas anaranjadas.

Referencias bibliográficas: Ortiz Romero y Rodríguez Díaz 1998: 264.

\section{Ermita de San José (Fig. 10, n.o 7)}

\section{Localización}

Se asienta sobre una cresta de cuarcita que forma parte de una elevación destacada de la ladera sur de la sierra del Arrozao. El entorno inmediato está formado por terrenos muy pedregosos de suelos poco profundos, ocupados por pastizal y matorral. Domina la vega de un pequeño arroyo que desciende de la sierra, ocupada mayoritariamente por cultivos de cereal en secano.

\section{Estructuras}

Se distinguen numerosas alineaciones de muros que conforman un conjunto edificado de planta muy irregular sobre el farallón cuarcítico y sus laderas $\mathrm{S}$ y SE. Su longitud máxima es de unos 38 metros y su 

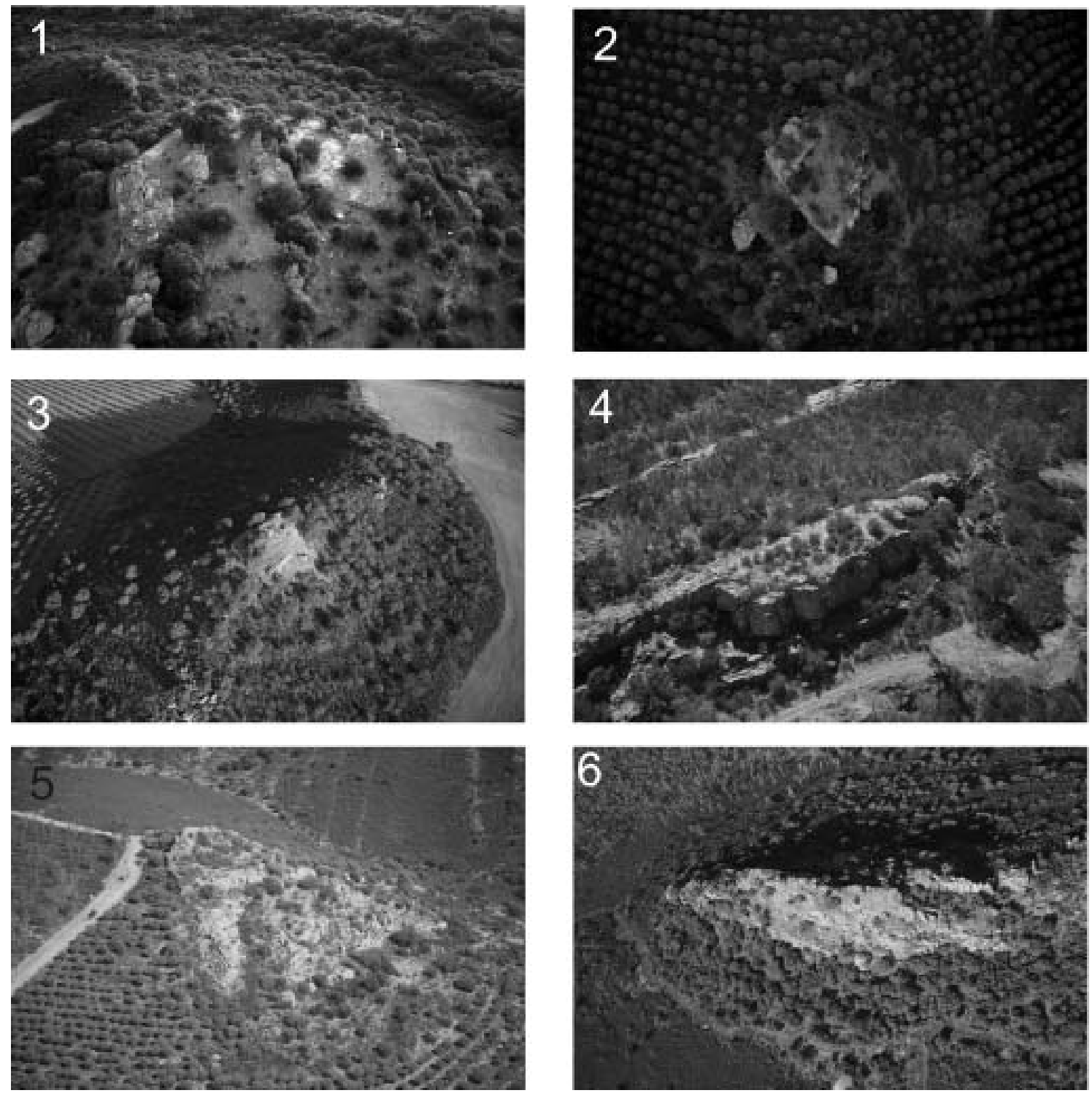

Figura 9. Vistas aéreas de los casos estudiados. 1.-Merchanas; 2.-Castildavid-Lapa; 3.-Castillejo del Moro; 4.-sierra del Castillo del Portugués 2; 5.-sierra del castillo del Portugués 1; 6.-La Dehesilla. Fotografías: Jesús Rueda y Victorino Mayoral.

anchura de 30 metros. El aparejo de los muros es de mampostería a seco de bloques de cuarcita con cuñas y calzos para encajar en la roca madre. En la parte más alta se aprecia una estructura cuadrangular de reducidas dimensiones (unos cinco metros de lado), cuyo muro de cierre cubre los espacios entre los salientes rocosos. Hacia la ladera $\mathrm{E}$ y de forma escalonada se distinguen hasta tres ámbitos aterrazando la ladera. Al pie del farallón y por su lado E varios muros alargados de mayor grosor y aparejo delimitan un recinto más amplio, de unos 300 metros cua- drados. En la ladera N se distingue una depresión artificial en el terreno que parece corresponder a una charca o depósito.

\section{Materiales arqueológicos}

Se reconocieron en superficie algunos fragmentos de pastas groseras correspondientes a grandes contenedores de producción local (Fig. 13, n.. 11,20 , 21) así como comunes con formas cerradas media- 
nas de almacenaje (Fig. 13, n. ${ }^{\circ}$ 9, 10, 12, 13) y servicio de mesa (Fig. 13, n.o 17 y 18). También se encontró cerámica oxidante de tradición indígena con decoración de bandas pintadas (n.․ 19). Aunque muy fragmentada y escasa, se detectó una muestra de materiales romanos: dos pequeños fragmentos de terra sigillata: hispánica de la forma 33 (Figura 13 (B), n.o. 9) y sudgálica Drag. 15/17 (Figura 13 (B), n..$^{-11)}$, y otros dos de paredes finas béticas (Figura 13 (B), n.․․ 8 ) y emeritense (Figura 13 (B), n. 9) (Fig. 13, n. 14 y 16), así como fragmentos de lucernas. Estos elementos permiten hablar al menos de una ocupación altoimperial, aunque la relación con materiales de tradición indígena y las estructuras ciclópeas no queda clara por el momento.

Referencias blibliográficas: pese a la falta de referencias precisas publicadas parece corresponderse con el sitio de Canchos de Merenilla (Ortiz Romero y Rodríguez Díaz 1998: 264).

Sierra del Castillo del Portugués 1 (Fig. 9, n. 5 , Fig.10, n.ㅇ 6)

\section{Localización}

Se localiza en un espolón destacado de la ladera meridional de la sierra del Arrozao. La fortificación se adapta completamente a la forma de un afloramiento cuarcítico. El terreno es muy accidentado y dominado por matorral y monte bajo. El entorno está muy afectado por la repoblación con eucaliptos. Desde la cima se tiene un completo dominio visual hacia el SE, S y SO, controlando la vega del Arroyo Tamujoso y del corredor del Guadamez.

\section{Estructuras}

Se identifican dos recintos principales. El de mayor altura se localiza en el extremo N, es de reducidas dimensiones y planta rectangular. Queda cerrado por el $\mathrm{N}$ por un escarpado risco. El desnivel en esta zona de conexión con las elevaciones del la sierra es acentuado por una depresión artificial que parece corresponder a un foso excavado en el terreno. Lo separa del segundo recinto una serie de muros que cierran el espacio entre los afloramientos. El segundo recinto, más amplio, se extiende al pie del primero. Presenta varios aterrazamientos en los que se aprecian diversas alineaciones de muros y abundante material constructivo. El cierre de este sector aprovecha la defensa natural de los salientes rocosos, que se complementa con gruesos muros apoyados directamente en el sustrato. La estructura de mayor volumen es un potente bastión que domina el ángulo NO del perímetro (Fig.11, 2). El aparejo es de mampostería de cuarcita a seco, y a juzgar por los restos superficiales tendrían alzados de adobe. Los muros se encajan en terraza directamente sobre la roca madre con ayuda de calzos. En la ladera sur y al pie del segundo recinto se aprecian pequeñas zonas aterrazadas con acumulación de sedimentos y presencia de cerámica que podrían corresponder a una extensión del asentamiento. También en este sector se distinguen con claridad las zonas de extracción del material empleado para la construcción.

\section{Materiales arqueológicos}

Debido al intenso arrasamiento del sitio se documenta en superficie una gran cantidad de cerámicas: producciones toscas de fabricación local para grandes contenedores (Fig. 8, 6-7), así como recipientes de cocina. También existe una amplia gama de recipientes de cerámica común con pastas en general depuradas de tonos anaranjados: vasos, platos, cuencos y ollas. En este grupo se documenta la decoración con bandas horizontales pintadas en rojo vinoso. En ningún momento detectamos la presencia de material latericio.

\section{Referencias bibliográficas}

Ortiz Romero y Rodríguez Díaz (1998: 264) citan la presencia de una fortificación en el inmediato paraje de Los Vuelos, sin aportar referencias precisas sobre su localización ni aclarar si se está refiriendo a los dos asentamientos documentados en este lugar (Portugueses 1 y 2).

Sierra del Castillo del Portugués, 2 (Fig. 9, n.o 4, Fig.10, n.o 5)

\section{Localización}

Se localiza en una cresta cuarcítica que se destaca en espolón en la ladera sur de la sierra del Arozao. Está situado a unos 340 metros de la fortificación de sierra del Portugués 1. El terreno es muy abrupto y ocupado por matorral y monte bajo junto con una repoblación reciente de eucaliptos. 


\section{Estructuras}

El conjunto presenta una planta alargada de unos 43 por 18 metros, que se adapta a los farallones rocosos. La ladera norte presenta un corte vertical de gran altura y apenas se aprecian en ella estructuras. Por este lado se distingue un posible acceso, flanqueado por un bastión de planta ovalada de unos 5 metros en su radio mayor. Desde aquí se accede a una estructura cuadrangular de gruesos muros de mampostería de cuarcita de unos nueve metros de lado, que domina la parte más alta del asentamiento. En una plataforma inferior el saliente rocoso define un segundo recinto, más amplio (unos 400 metros cuadrados). Queda delimitado hacia el sur por una potente muralla de mampostería que apoya directamente sobre la roca madre y se adapta con un trazado sinuoso a su contorno a lo largo de casi 50 metros (Fig.11, 3). La técnica de los muros es muy similar a la de la sierra del Portugués, aunque se distingue en algunos tramos un aparejo de piedra más pequeña y factura menos cuidada. Según se ha propuesto en un reciente estudio (Pizzo 2010: 168), estas diferencias responden a la presencia de al menos dos fases constructivas, y demostrarían la existencia en un primer momento de un proyecto común de construcción de éste sitio y el Portugués 1.

\section{Materiales arqueológicos}

El repertorio de hallazgos superficiales es muy similar al de Los Portugueses 1. Cabe destacar la presencia de ánfora de tradición ibérica, así como el hallazgo de un fragmento de gran contenedor de factura tosca con decoración estampillada (Fig.8, 11). Como en el anterior, no hay ningún indicio de material latericio.

Castillejo de Moros (Fig. 9, n.o 3, Fig.10, n.o 3)

\section{Localización}

Las construcciones ocupan la cima de un cerro aislado de sustrato cuarcítico que domina el valle del Guadamez, a unos 700 metros de éste. El terreno está actualmente ocupado por matorral, encinar y monte bajo. Esta elevación se destaca entre el río y las cimas de la sierra de la Lapa. Entre estas últimas y el asentamiento se localizan los «llanos del moro», una amplia franja de terrenos dedicados al cultivo de secano.

\section{Estructuras}

Las estructuras identificadas se distribuyen formando tres recintos concéntricos. El localizado en la cima tiene una planta rectangular con unas dimensiones de unos 14 por ocho metros. Los muros tienen un alzado a plomo formado por grandes bloques poligonales de pizarra muy bien careados, con un grosor de entre 1,40 y 1,60 metros. Un segundo nivel aterrazado queda delimitado por un muro que recorre todo el costado occidental. El aparejo es de grandes lajas a seco que se apoyan directamente en la roca. Finalmente, un tercer ámbito se define por una plataforma que se extiende por los costados sur y sureste del segundo recinto, rodeada por un muro de doble paramento de 1,30 m de grosor cuyo trazado se adapta a los afloramientos rocosos y definiendo una plataforma de unos 380 metros cuadrados. La presión de los rellenos de su cara interna ha provocado grandes derrumbamientos.

\section{Materiales arqueológicos}

El material superficial de este sitio consiste en fragmentos en general muy rodados de grandes contenedores de factura tosca (Fig. 13 (A), n. ${ }^{\text {os }} 1$ al 5), junto con algunas cerámicas comunes de almacenaje (Fig. 13 (A), n. o 6), y de vajilla de mesa (Fig. 13 (A), n. ${ }^{\text {s }} 7$ y 8 ). Se recuperó un pequeño fragmento de terra sigillata. No existía material latericio en superficie ni en los numerosos cortes provocados por la actividad reciente de expoliadores.

\section{Referencias bibliográficas}

Rodríguez Díaz y Ortiz Romero, 1989: 51; Venegas, 1995: 164.

Castildavid o La Lapa (Fig. 9, n.o 2, Fig. 10, n. 2)

\section{Localización}

El sitio ocupa una reducida plataforma delimitada por un risco de cuarcita que se destaca como un espolón sobre uno de los arroyos que descienden desde la sierra de la Lapa hacia el Guadamez. El terreno es muy accidentado y su uso actual es de matorral y monte bajo, con repoblación reciente de pinos. 


\section{Estructuras}

Se diferencian con claridad dos recintos en alturas diferentes. En el punto más alto se identifica una estructura rectangular de mampostería de cuarcita que fortifica la parte más abrupta del afloramiento (véase su alzado en la figura 11,1 ). Un segundo perímetro más amplio queda cerrado por su lado por un potente muro de bloques de cuarcita de aparejo ciclópeo colocados a seco directamente sobre la roca. En todo su perímetro salvo en su lado SE ésta presenta un corte vertical de gran altura que lo hace totalmente inaccesible. En planta el trazado de este segundo recinto se adapta estrechamente a los quiebros del cantil formado por el afloramiento. Además este último ha sido recortado para regularizar la base del muro. En el interior, que presenta una fuerte pendiente, se diferencian también alineaciones correspondientes a la cimentación de estructuras.

\section{Materiales arqueológicos}

En superficie se ha recuperado sobre todo fragmentos de grandes contenedores de pastas groseras, destacando el hallazgo de varios bordes de ánfora de tradición ibérica (Fig. 8, 1-2), junto con piezas de cerámica común como platos y cuencos de pie anular (Fig. 8, 4-5) y algunas formas de almacenaje de tamaño medio. En ninguna de las exploraciones del sitio se ha identificado material de importación ni restos constructivos de filiación romana.

\section{Referencias bibliográficas}

Rodríguez Díaz y Ortiz Romero 1989: 51; Venegas 1995: 166.

\section{Puerto de la Cabra (Fig. 10, n.o 4)}

\section{Localización}

Se localiza a lo largo de una cresta cuarcítica en la cima de la sierra del Puerto de la Cabra, a unos 600 metros de éste último. El terreno está ocupado por pastizal y matorral, con algunos acebuches y encinas, aunque predomina el jaral y el eucalipto introducido por la repoblación. El dominio visual es amplísimo, especialmente desde la vertiente $\mathrm{N}$, desde la que se divisa un arco que va desde las sierras de
Orellana hasta la sierra de Carija en las inmediaciones de Mérida.

\section{Estructuras}

Las estructuras se distribuyen alrededor y sobre dos grandes salientes rocosos. En planta se definen tres sectores bien diferenciados. En la cima del saliente situado al sureste se localiza una estructura cuadrangular de 9,5x9,5, en cuyo lado SE destaca unos tres metros un cuerpo rectangular. Queda delimitada por todos los lados por un corte vertical en la roca, que presenta un fuerte desnivel, especialmente por la cara norte. El acceso se realiza por la cara Noroeste mediante un estrecho pasillo exterior de 1,60 metros de anchura, que conecta la estructura con la plataforma inferior a través de una escalera. Esta está en parte tallada en la roca y en parte construida mediante un macizado de tierra apisonada recubierto con losas de cuarcita. En el saliente noroccidental no se reconocieron estructuras con claridad, aunque sí algunos bloques de cuarcita colocados in situ.

El segundo sector está delimitado por una cinta muraria que cierra el espacio entre los dos farallones rocosos, formando dos plataformas. La primera se localiza al sureste de la estructura de la cima y cuenta con un acceso al exterior del complejo. La segunda abarca el espacio entre los dos salientes. Comunica con la estructura de la cima a través de la escalera ya mencionada. Está cerrada al $\mathrm{N}$ y al $\mathrm{S}$ por una potente muralla, y por éste último lado presenta un acceso al tercer sector.

Éste último consiste en un tercer recinto amurallado que se extiende por una superficie de al menos 250 metros cuadrados en la vertiente suroccidental, aunque es posible que esta extensión sea el doble, ya que en esta zona la vegetación era espesa y resultaba muy difícil reconocer el terreno.

\section{Materiales arqueológicos}

El material identificable en superficie era muy escaso, compuesto por galbos de vasijas de almacenaje y cocina de factura tosca, junto con algunas cerámicas comunes de vajilla de mesa como cuencos.

\section{Referencias bibliográficas}

Ortiz Romero y Rodríguez Díaz 1998: 264; Rodríguez Díaz y Ortiz Romero 1989: 51. 

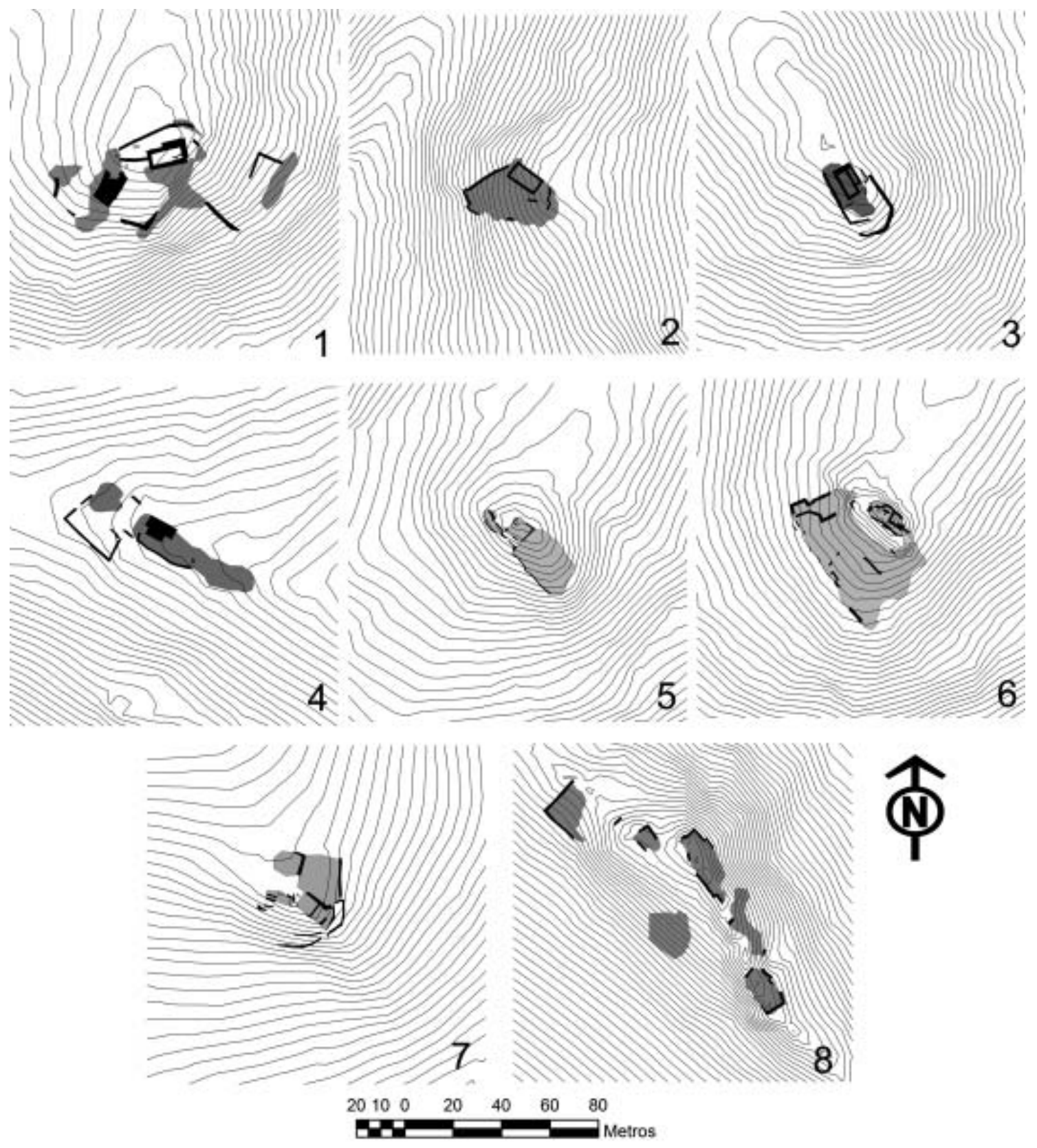

Figura 10. Comparativa de las plantas de fortificaciones de altura. 1.-Las Merchanas, 2.-Castildavid/La Lapa; 3.-Castillejo del Moro; 4.-Puerto de la Cabra; 5.-Portugués 1; 6.-Portugués 2; 7.-Ermita de San José; 8.-La Dehesilla.

\subsection{Discusión}

Comenzaremos esta valoración conjunta de las Merchanas y los asentamientos fortificados de su entorno, considerando el tamaño y planta de los casos expuestos más arriba. Hemos calculado la superficie total en hectáreas ocupada por restos construc- tivos identificables en superficie para todas las fortificaciones de altura que tenemos catalogadas. El caso más destacado en este sentido queda fuera del sector en el que hemos centrado nuestra atención. Se trata de Puerto Mejoral (Benquerencia de la Serena), con cerca de media hectárea. Con extensiones de cerca de la mitad que el anterior, y como los dos únicos casos 


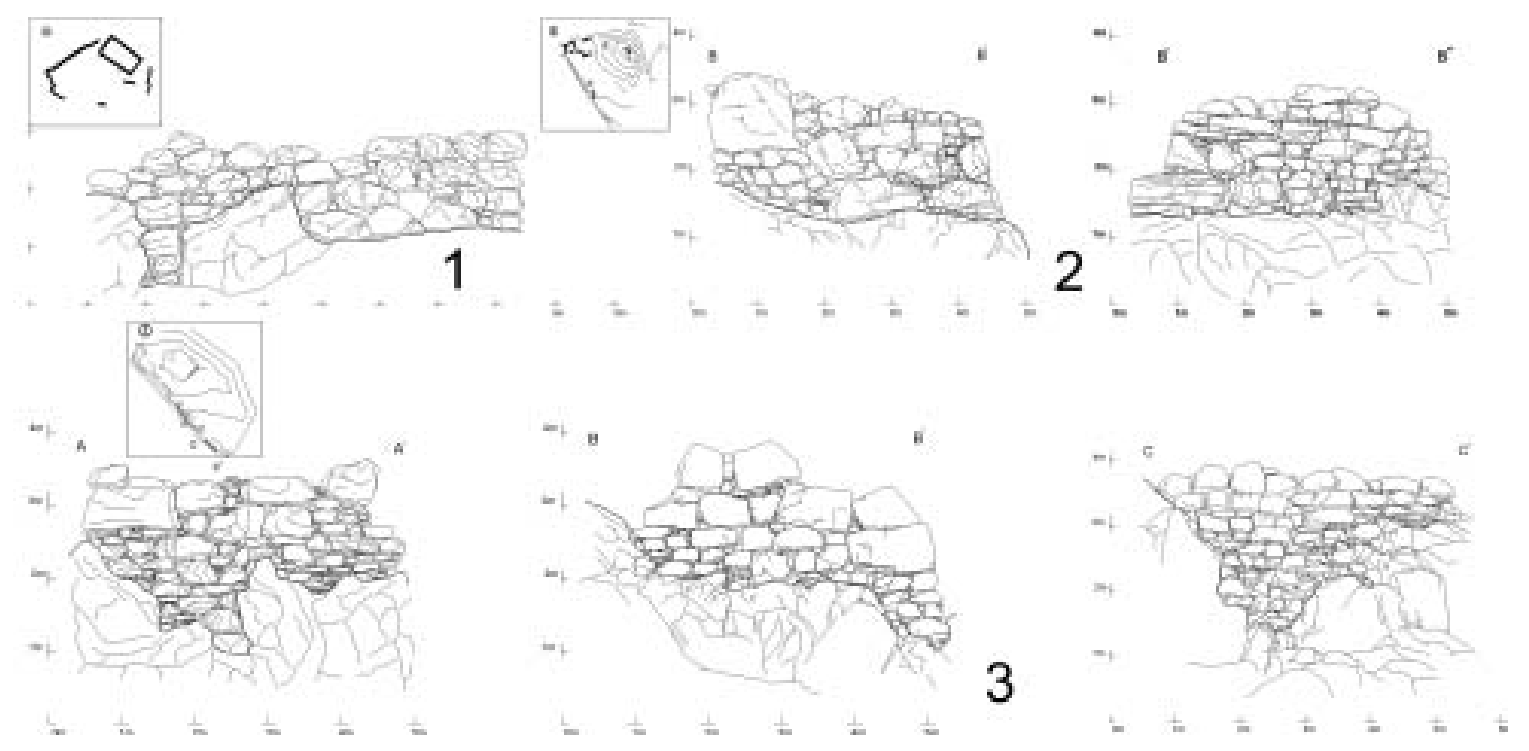

Figura 11. Alzados de las fortificaciones de La Lapa (1), Castillo del Portugués 1 (2) y Castillo del Portugés 2 (3).

de asentamientos grandes en la zona del Guadamez, destacan el Castillo del Portugués 1 y la propia Merchanas. Ambos sobresalen además por la complejidad y monumentalidad de sus estructuras. Por otro lado, nos parece necesario valorar al primero de los citados conjuntamente con Castillo del Portugués 2.

Les sigue un grupo homogéneo en dimensiones (en torno a 500-600 metros cuadrados), formado por Castillo del Portugués 2, Castillejo del Moro, La Lapa y Puerto de la Cabra. A este conjunto también habría que añadir casos como el del Castillejo de los Argallanes (Higuera de la Serena), aunque no nos hemos ocupado en este trabajo de su descripción más detallada. Todos ellos tienen además una planta de diseño muy similar, que parece reproducir a una escala más reducida el de Merchanas, y en especial el de Castillo del Portugués 1. Un elemento común del mismo es la presencia en la cima de una estructura rectangular de medidas (unos once por ocho metros de media) y superficies muy parecidas (en torno a los 100 metros cuadrados). Al costado de la misma y a una altura más baja suele localizarse un segundo recinto, en cuyo interior se han identificado alineaciones que revelan la existencia de construcciones de mampostería. Un caso que rompe esta homogeneidad es el de la Dehesilla, con una planta mucho más irregular en la que la adaptación al terreno prima sobre la imposición de un diseño previo.

Por lo que respecta a las técnicas constructivas, la revisión que hemos llevado a cabo pone de manifiesto una estrecha conexión entre las soluciones adoptadas en Merchanas y el resto de los sitios estudiados. En esta sección seguimos en parte las conclusiones de un estudio, ya citado, realizado por Antonio Pizzo. El primer elemento común es el empleo de la cuarcita, hecho que obviamente se deriva de los emplazamientos seleccionados. Es por tanto una técnica que aprovecha al máximo los recursos disponibles en el entorno inmediato, dejando de hecho una traza material en las zonas de extracción. Esta adaptación es también relativa a las peculiaridades morfológicas de la geología dominante, empleando el perfil abarquillado de los viejos pliegues cuarcíticos como la mejor base para cerrar un perímetro defensivo. Se observa de manera reiterada la presencia de las mismas soluciones técnicas en función del papel desempeñado por las estructuras. Por un lado, encontramos grandes muros de aterrazamiento que suelen delimitar los recintos situados en las cotas más bajas, como ocurre en Puerto de la Cabra, La Lapa, Castillejo del Moro o en las propias Merchanas (Fig. 12: 3, 5, 9, 11). Sus aparejos son verdaderamente ciclópeos, a base de bloques poligonales a seco. En ocasiones actúan como contrafuertes para estructuras superiores o para reforzar las estructuras de la cima, adoptando un perfil ataludado (Merchanas, Castillejo del Moro, Castillo del Portugués 1) (Fig. 12: 1, 4, 7). Por otro, en estas últimas encontramos un aparejo de menor porte, con hiladas muy regulares que se agarran a la base rocosa mediante calzos, un cuidadoso careado y una depurada técnica para cubrir los huecos con ripio (Fig. 12: 

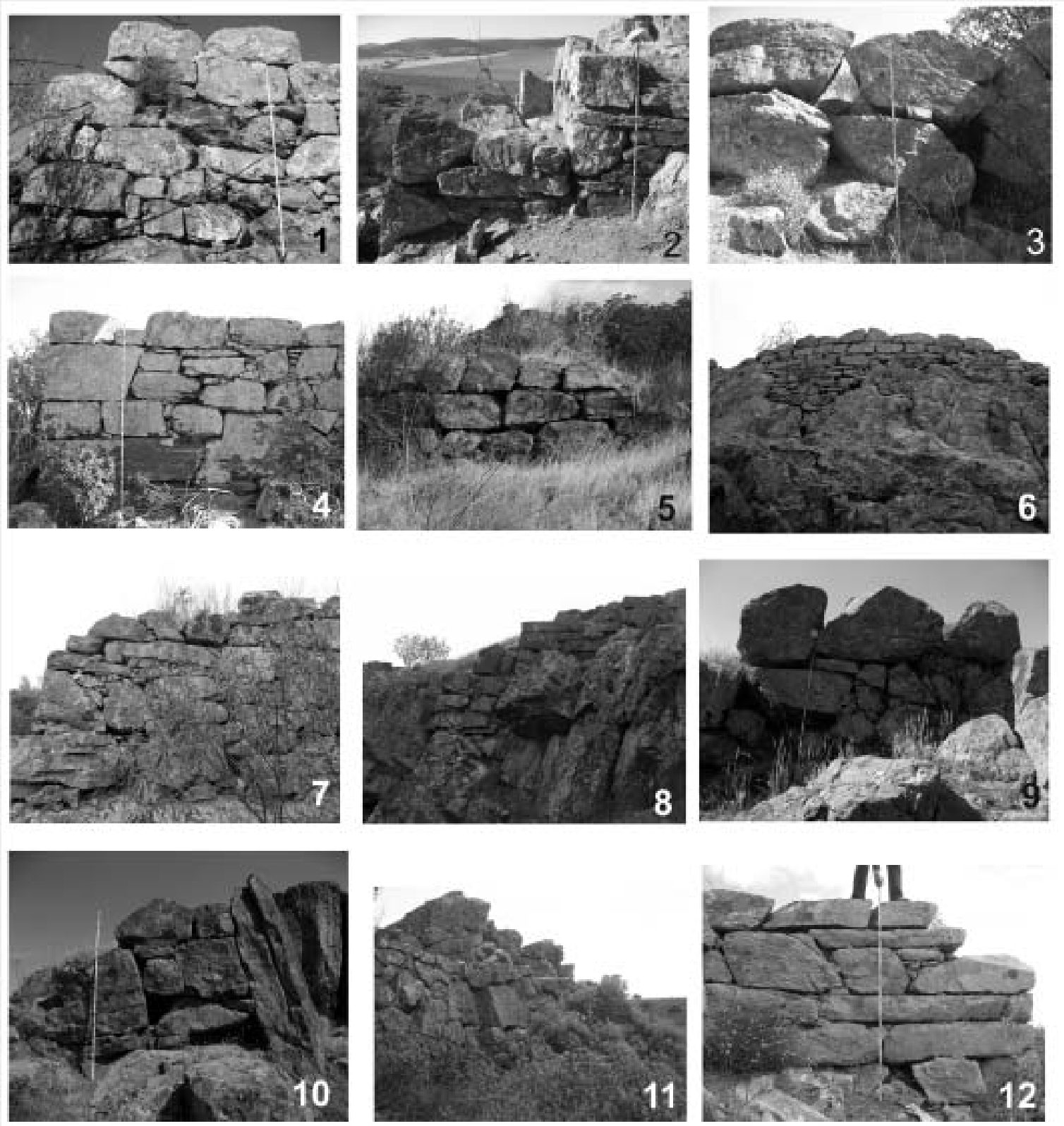

Figura 12. Diversos aspectos de los aparejos de las fortificaciones estudiadas. 1-3.- Merchanas; 4.-Castillejo del Moro; 5.-La Lapa; 6.-Portugueses 2; 7-8.- Portugueses 1; 9-10.- La Dehesilla; 11-12.-Puerto de la Cabra.

$8,10,12)$. En esta ajustada adaptación a un entorno sumamente escarpado se pone de manifiesto la gran pericia técnica de los constructores que, en opinión del ya citado A. Pizzo, constituyen una mano de obra muy especializada. Son por otro lado reiterados los indicios de alzados de tapial o adobes sobre los zócalos de mampostería. Por último, por lo que respecta a los sistemas de cubierta, en ninguno de los casos se ha detectado una masa significativa de material latericio de cuño romano, estando ausente por completo en la mayoría de los sitios. Como ya se ha propuesto, la abundancia de lajas de pizarra en la cima de Merchanas permite sugerir el empleo de este material como parte del techado.

Finalmente, en lo que se refiere a los materiales arqueológicos, la contrastación del registro de Merchanas, tanto con el servicio cerámico localizado en los otros sitios como con el de algunos recintos en 
llano, que también estamos estudiando (caso del Cerro del Tesoro o Cancho Roano), nos permite aportar elementos para una evolución diacrónica de este tipo de construcciones en la Serena.

Como ya vimos, el material hasta ahora conocido en Merchanas permite acercarnos genéricamente a su diacronía. Claramente observamos una ocupación de finales de la Edad del Hierro que vendría dada por los elementos pintados, las urnas truncadas o las pastas cerámicas grisáceas asalmonadas con acabados bruñidos, que se asemejan como ya hemos visto a elementos cerámicos localizados en otros puntos del suelo extremeño como en Botija (Hernández et al. 1989) o en la Baeturia (Berrocal 1998). Si valoramos las producciones importadas, la aparición del ungüentario de tradición helenística nos sitúa en el tránsito del II-I a.C. En segundo lugar, un fragmento de sigillata itálica aretina, así como cerámicas comunes que distan mucho del panorama normal de época romana de la zona (Alvarado, Molano 1995), ofrecen indicios de ocupación para los primeros momentos del Imperio. Finalmente, un galbo de terra sigillata hispánica, de posible procedencia de los talleres del Najerilla, puede hablar de una ocupación del cerro al menos hasta la época Flavia.

¿Dónde encaja dentro de esta secuencia el momento de construcción de las fortificaciones? La investigación precedente plantea que el origen de este fenómeno se remontaría al período tardorrepublicano, posiblemente a inicios del siglo i a. C. En reiteradas ocasiones se ha mencionado la presencia en los sitios de altura de cerámicas con técnicas y formas de raigambre indígena. Encajan dentro de esta categoría las ánforas de labio engrosado y borde envasado, los cuencos y platos de pie indicado, o las estampillas de gran tamaño en contenedores de factura tosca, como el identificado en el Portugués 2. Sin embargo, en ausencia de elementos inequívocamente tardorrepublicanos es precisamente su carácter de tradición el que hace perfectamente posible que se fechen en una etapa más tardía. Por lo que respecta a nuestro propio trabajo de prospección, ya hemos visto varios casos claramente relacionados con Merchanas por su planta y técnicas constructivas, en los que, pese al intensivo rastreo de superficie, no se ha localizado ningún material claramente adscribible a época imperial (sierra del Castillo del Portugués 1 y 2, Puerto de la Cabra, La Lapa y Alto de la Dehesilla), pero sí conjuntos cerámicos de carácter indígena. Ello nos inclina a pensar que estamos ante un sistema de fortificaciones cuya evolución es desigual en el tiempo, con casos tempranamente abandonados frente a otros que perduran hasta la plena etapa imperial.
Es difícil con la evidencia disponible hablar en estos últimos de ocupación continuada o reutilización de antiguos enclaves. Lo que queda claro es que, como ya se ha expuesto, se han recuperado importaciones romanas de cronología imperial en Ermita de San José y Castillejo del Moro. Obviamente el criterio ex silentio de estos materiales en los otros sitios no es del todo concluyente, ya que la frecuencia relativa de los mismos en los conjuntos cerámicos no es tan elevada como las producciones comunes. Es igualmente claro que en estas últimas encontramos abundantes ejemplos de la pervivencia de tradiciones locales hasta época Julio-Claudia avanzada, fenómeno que se pone bien de manifiesto a través de conjuntos como el del recinto de llano del Cerro del Tesoro (Bustamante, 2010). Un aún deficiente conocimiento de las producciones a escala regional nos impide percibir con nitidez hasta qué punto se alargan dichas perduraciones. Por lo que respecta a las estructuras visibles, se detecta en algunos de estos sitios la presencia de adobes, así como la falta de materiales y técnicas constructivas de factura romana. Sin embargo, esta ausencia de evidencia tampoco resulta concluyente, ya que no sería extraño en emplazamientos tan poco accesibles recurrir a métodos basados en los materiales más disponibles (alzados de tierra, cubiertas vegetales y de barro...).

Junto con los atributos estrictamente arqueológicos de los sitios estudiados, hemos intentado ofrecer una valoración sintética e indirecta de sus características a través de la cuantificación de variables que se estiman significativas en la toma de decisiones respecto a su ubicación. La hipótesis de partida es que las diferencias ya señaladas en cuanto a la estructura y diseño de las fortificaciones guardan algún tipo de relación con el papel desempeñado por estos asentamientos.

Una manera sencilla de objetivar estas posibles diferencias sería valorar el grado de accesibilidad y prominencia topográfica de los emplazamientos. De entre los posibles métodos para el cálculo de la altitud relativa, hemos optado por el empleado por Parcero y Fábrega (2006: 17-18) en su estudio sobre las pautas de localización de los asentamientos castreños. Dichos autores se sirven de la diferencia entre la cota más alta de cada sitio y el valor medio de la altimetría en un determinado radio de distancia en torno al mismo. Dividiendo este valor por la desviación estándar en ese rango, crea un índice normalizado para esta variable, atenuando el efecto de los valores absolutos de cada caso. Siguiendo la misma estrategia que en el citado caso de estudio, obtuvimos los valores de altitud relativa para valorar el entorno inmediato (500 


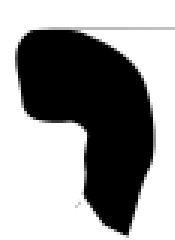

230

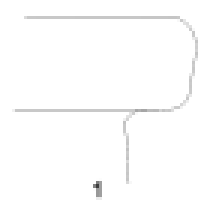

ร 34
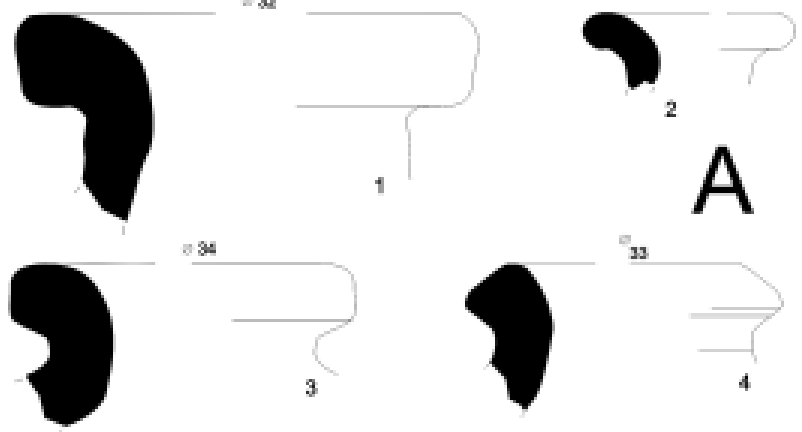

3
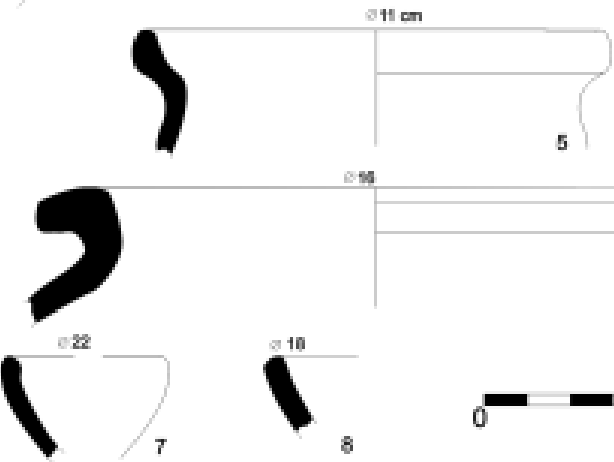

5

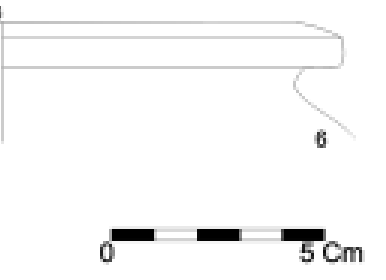

8

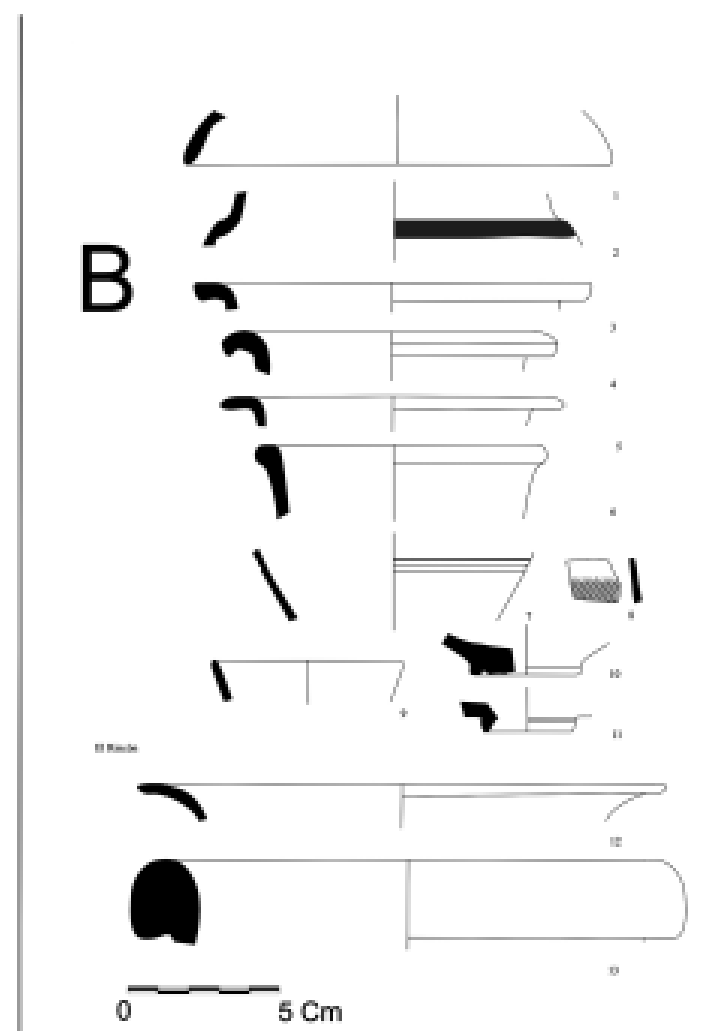

Figura 13. Selección de material de superficie del Castillejo del Moro (A). 1 a 5, producciones de pasta grosera. 6 al 8 , cerámicas comunes. (B) Ermita de San José.

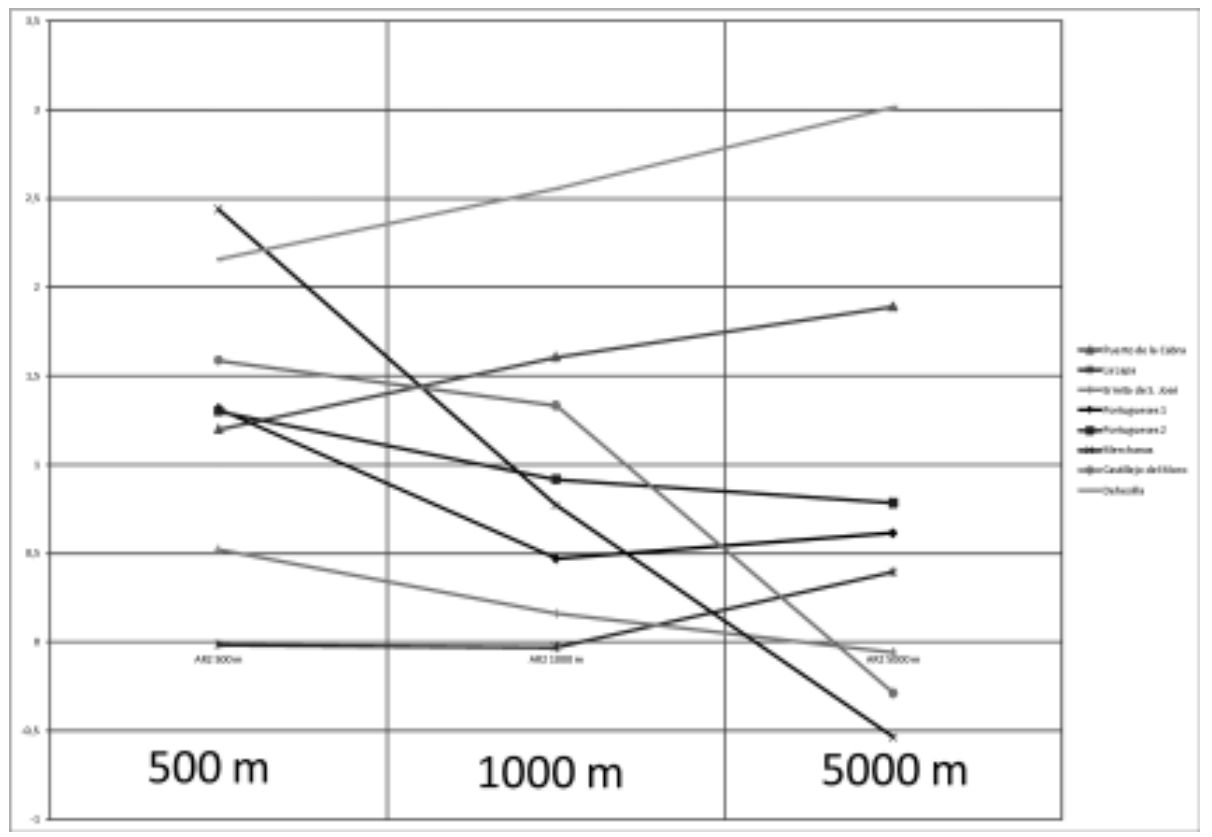

Figura 14. Gráfico con la variación en función de la distancia de las altitudes relativas normalizadas de los casos estudiados. 

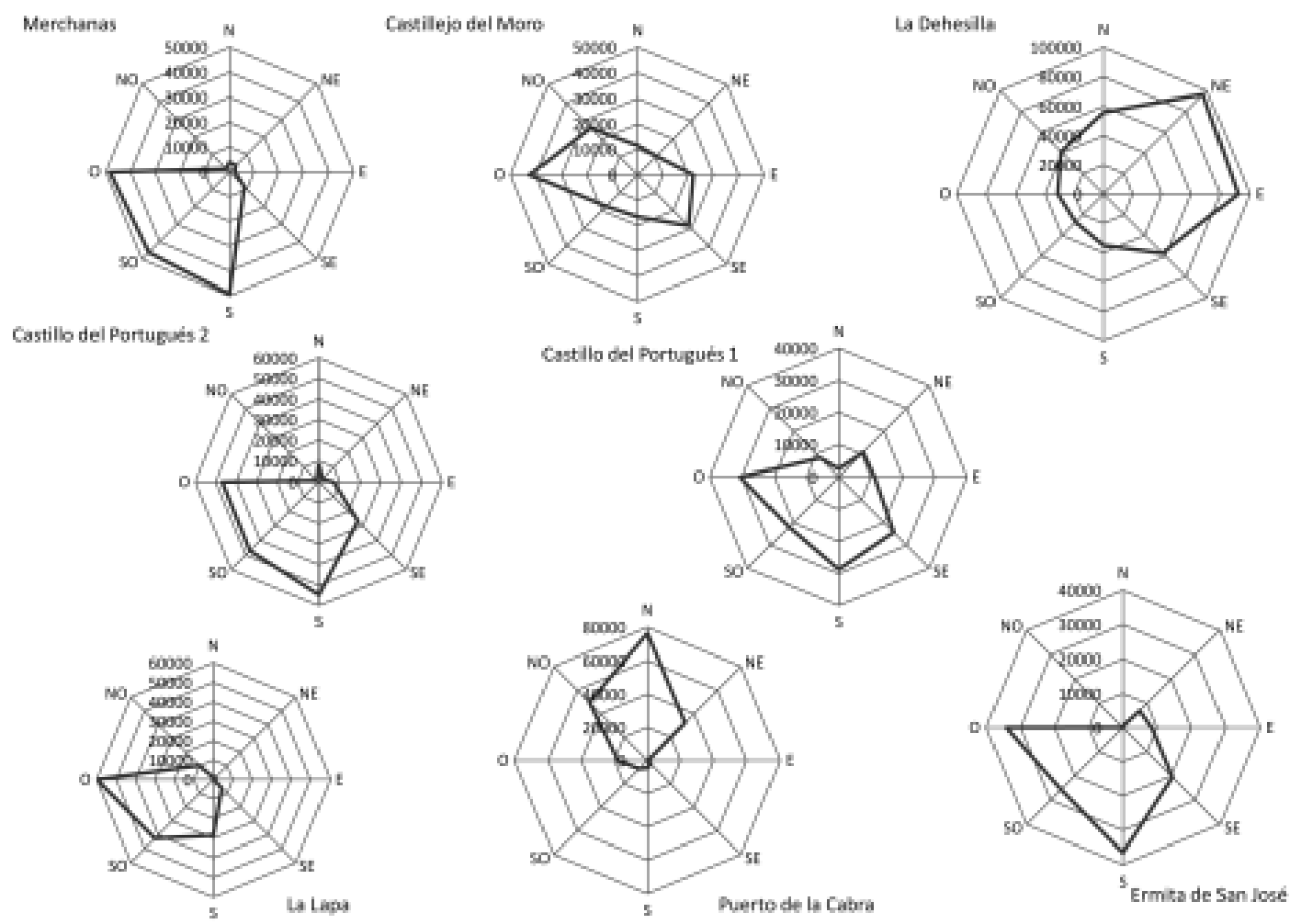

Figura 15. Gráfico con la extensión en metros cuadrados y direccionalidad del dominio visual de las fortificaciones en un radio de cinco kilómetros.

metros), medio (1000 metros) y lejano (5000 metros) de nuestras fortificaciones (Fig. 14).

El resultado es que este índice facilita la identificación de dos pautas bien diferenciadas. Contamos en primer lugar con un conjunto de sitios con tendencia a destacar más en el paisaje a medida que aumenta la distancia. Es el caso sobre todo de Puerto Cabra, La Dehesilla, y en menor medida la Lapa. Muestran la tendencia contraria, es decir, a camuflarse en el paisaje destacando sólo en el entorno más inmediato, Ermita de San José, Castillejo del Moro y las Merchanas. Estos dos últimos muestran una tendencia muy acusada, sobre todo si se valora el índice normalizado. Son precisamente estos tres últimos casos los que por el momento ofrecen en superficie materiales de época imperial.

Por lo que respecta al control visual del entorno desde cada sitio, fue valorado de modo directo con las observaciones de campo. No obstante, a fin de trabajar con un indicador cuantitativo y comparable para esta variable, se han calculado cuencas de visibilidad para analizar tanto la capacidad global desde cada sitio como su variación en función de la direccionalidad. Para definir los puntos de observación se ha tomado como referencia el centro y las esquinas de la estructura rectangular situada en la parte más alta de los recintos. Se ha tenido en cuenta una altura hipotética de 5 metros para las estructuras, valorando rangos de distancia de entre 500 metros y 5 kilómetros. Para la altimetría se ha tomado como referencia un modelo TIN generado a partir de las curvas de nivel, puntos de cota e hidrografía del mapa topográfico digital de Extremadura a escala 1:10.000. Para la realización del cálculo se ha empleado el módulo Viewshed de Arcgis (v. 9.3), superponiéndose luego con un mapa de direcciones que permite calcular la superficie de terreno observable en función de los puntos cardinales. Nos parece oportuno apuntar que en ningún caso estos cálculos se han realizado con el propósito de obtener una reconstrucción positiva del dominio visual desde las fortificaciones, sino para facilitar la comparación entre casos.

En general, resulta patente un control muy focalizado y con una orientación bastante marcada hacia el fondo de los corredores que enmarcan las sierras. En algunos casos no parece existir interés por localizaciones cercanas capaces de proporcionar un arco visual mucho más amplio a lo largo de esos pasillos, 


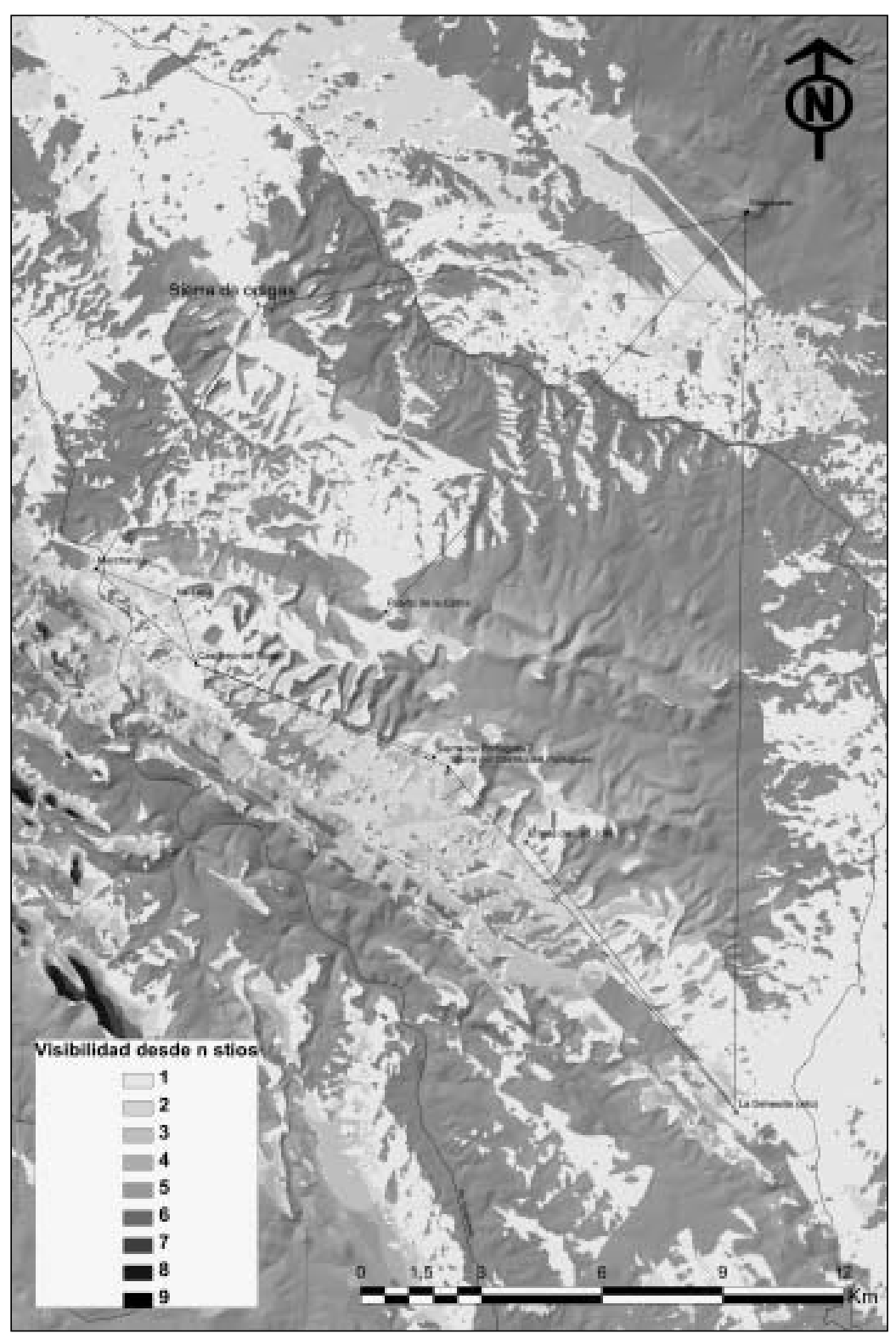

Figura 16. Mapa de visibilidades acumuladas desde los casos estudiados.

extensión total de terreno controlado visualmente.

Otro aspecto que estimamos de importancia es el de las relaciones de intervisibilidad (Fig. 16). Resulta evidente su importancia dentro de una argumentación que valora estas fortificaciones como un sistema organizado de control territorial. En este sentido, y siempre a partir de los parámetros que hemos expuesto, las conexiones entre el grueso de los sitios valorados define con bastante claridad una cadena a lo largo del corredor que conecta las cuencas del Ortigas y Guadamez, y que desemboca en la del Guadiana. Al mismo tiempo, pensamos que sitios como Castillo del Portugués 1 y 2 o Puerto de la Cabra tienen más que ver con un control en sentido transversal, vigilando pasos secundarios. A su vez este último caso prolonga el dominio visual hacia toda la vega alta del Guadiana, y más en primer plano al valle que conecta Magacela con el entorno de Medellín. Sin embargo, es llamativo que precisamente un asentamiento clave como éste quede oculto por la única zona ciega de ese amplísimo arco de visibilidad. Impide verlo la presencia de la sierra de Ortigas, que según algunas propuestas sería el límite natural del territorio del ager Metellinensis (Haba

quedando encajonados entre dos elevaciones más destacadas. De hecho, con la excepción de La Dehesilla, no buscan los puntos más prominentes y las líneas de crestas que compartimentan el paisaje para obtener un control de todas las vertientes, sino que se quedan a media altura, dejando a sus espaldas amplias zonas sin visualizar. El gráfico de la figura 15 resulta bastante elocuente en este sentido. Esta homogeneidad queda también reflejada, salvo en el caso de La Dehesilla, en unas proporciones muy similares de la
1998: 17). Desde allí es posible divisar tanto el Puerto de la Cabra como Las Merchanas. Una visita a las cimas de esta elevación deparó el hallazgo de materiales de diversa cronología, además de restos de estructuras de mampostería de cuarcita difíciles de interpretar debido a las fuertes alteraciones provocadas por la construcción de trincheras y parapetos durante la Guerra Civil. En cuanto a la cerámica, en torno a las citadas estructuras se detectó una concentración de fragmentos de urnas, cuencos y platos de 
fábrica común oxidante, junto a algún gran contenedor de factura tosca. Pueden reconocerse algunas formas de adscripción romana, pero en conjunto la evidencia es poco concluyente para poder afirmar que en la cima de esta sierra hubiera existido una fortificación relacionada con las que se analizan este trabajo. La cuestión, empero, no carece de importancia, ya que pone sobre la mesa el problema del papel de Medellín en la articulación territorial durante los inicios de la dominación romana y su relación con el oppidum de Magacela.

Otra faceta de las localizaciones por la que nos hemos interesado es la de la morfología del relieve en el entorno de las fortificaciones. En este sentido consideramos que podrían ser de utilidad algunas técnicas de análisis desarrolladas desde la geomorfología y otras disciplinas afines. Sin embargo, el resultado nos ha planteado más interrogantes que respuestas. El principio fundamental de la morfometría es que es posible maximizar la extracción de información a partir de los modelos digitales de elevación, a fin de representar de un modo eficaz y sintético la compleja combinación de atributos que definen las diferentes formas de la superficie (véase Wood, 1996 para una descripción detallada). En particular, la caracterización morfométrica permite clasificar el terreno en seis tipos diferentes de formas (picos, crestas, pasos, planos, canales y fosas). El cálculo se realiza superponiendo al modelo digital una ventana, que examina la relación entre cada celdilla central y sus vecinas. La amplitud de esta es determinante en cuanto al nivel de detalle con que se analiza la orografía, ofreciendo una imagen más simplificada y sintética cuanto mayor es su tamaño. En nuestro caso optamos por estudiar el efecto de emplear ventanas de diferentes tamaños, para finalmente establecer en nueve metros el compromiso entre resolución y legibilidad en la ejecución del análisis (la prueba se implementó mediante el módulo r.param.scale de Grass).

Extrajimos el valor absoluto en hectáreas para cada uno de los 6 tipos, considerando un radio de 500 metros, uno, cinco y diez kilómetros en torno a cada uno de los sitios. Nuestra hipótesis de partida era que, al igual que en el cálculo de la altitud relativa, la distribución de los valores permitiría agrupar los casos de una manera significativa. El resultado fue que la proporción mantenida entre cada tipo morfométrico era sumamente parecida para todos los casos considerados. Esto a priori podría valorarse como un indicador de la homogeneidad del grupo en cuanto a los criterios de localización. El problema surgió cuando comparamos los valores de diferentes rangos de distancia, obteniendo el mismo efecto. Únicamente la distribución de valores para el morfotipo de zonas planas ofreció contrastes apreciables. La conclusión a la que nos llevaba este resultado es que la proporción entre los diferentes tipos de morfometría era independiente de la escala, y que por tanto no era una variable útil en la definición de los criterios locacionales. Sin embargo, la repetición de la prueba comparando las localizaciones de nuestros casos con las de los recintos ciclópeos del valle del Ortigas mostró finalmente un esquema bien diferenciado.

\section{ESPACIOS Y TIEMPOS EN TRANSICIÓN: SOBRE EL SIGNIFICADO HISTÓRICO DE LOS RECINTOS Y FORTIFICACIONES DE ALTURA}

A modo de conclusión, planteamos que El Castejón de las Merchanas puede definirse como un destacado punto de control territorial, inserto dentro de un sistema desplegado a lo largo de la conexión entre las vegas Altas del Guadiana y La Serena. Aunque la hipótesis más plausible es que dicho entramado se habría implantado a partir de finales del siglo II - inicios del siglo i a. C, la realidad es que mas allá de paralelos formales en cuanto a la técnica constructiva, o la presencia de tipos cerámicos con una gran ambigüedad cronológica, al menos por lo que respecta a los casos aquí considerados no podemos aportar con certeza una fecha inicial. Esto obviamente condiciona cualquier intento de contextualizar históricamente este fenómeno. La bibliografía precedente ha insistido reiteradamente en vincular las construcciones ciclópeas en su conjunto (incluyendo los denominados «recintos de llano» de los que hablaremos brevemente más abajo) con los acontecimientos militares que se habrían desarrollado en la región durante el conflicto sertoriano (81-73 a. C). Dentro del proceso general de paulatina injerencia romana en el suroeste peninsular, este momento marca el definitivo dominio estratégico del territorio, pero la magnitud de las construcciones documentadas invita a pensar en factores estratégicos de más larga duración.

Otra cuestión crucial para la que sigue sin existir una respuesta clara es la naturaleza de los grupos humanos que construyen y habitan estos emplazamientos. ¿Se trata de contingentes militares? Si valoramos como un posible indicador el grado de regularidad en sus plantas, o la evidencia de un proyecto constructivo, observamos pocas conexiones con el diseño de otros conjuntos de fortificaciones peninsulares. Así ocurre con el grupo de castella identificados en el sur de Portugal (Fabiao, 2002, con una re- 
visión sistemática del tema). De acuerdo con este autor estamos ante un fenómeno de una gran uniformidad tipológica, pero poco relacionable con una actividad castrense y fechable entre mediados y finales del siglo i a. C. Una mayor afinidad formal parece existir entre nuestros casos y los denominados fortines del Alto Alentejo, estudiados por Mataloto $(2002,2004)$. Tienen unas dimensiones de entre 500 y 1.500 metros cuadrados, y eligen emplazamientos en altura con fuertes defensas naturales, localizados con frecuencia en puntos estratégicos de la red de comunicaciones. Aunque no se han publicado plantas o levantamientos topográficos detallados, se ha descrito la presencia de una torre con potentes estructuras en la parte más alta. Sin embargo, partiendo del registro superficial de estos sitios, Mataloto plantea una cronología que arrancaría en la segunda mitad del siglo i a. C. Coexisten por tanto con los denominados recintos-torre, estructuras de aparejo ciclópeo que suelen localizarse en zonas más llanas. Para este autor se trata de dos fórmulas diferentes pero complementarias en el proceso de romanización de las áreas rurales del Alentejo.

Queremos por último citar otros casos de asentamientos fortificados en altura de época tardorrepublicana que tampoco parecen comparables a los aquí estudiados. Así, en la región murciana de Caravaca se han documentado una serie de sitios cuyas cronologías parecen definir una secuencia muy corta, centrada en el tercer cuarto del siglo i a. C. (Brotons y Murcia 2008). Estos asentamientos, a los que se atribuye una funcionalidad militar clara, han sido a su vez vinculados con fortificaciones en posiciones defensivas localizadas en las altiplanicies granadinas (Adoher et al. 2004, 2006), aunque no existe consenso acerca de su datación precisa (Diosono 2005). En resumidas cuentas, de todo esto se desprende que en nuestra muestra prima la adaptación al terreno, y es poco concluyente la búsqueda de paralelos formales con otros enclaves para poder hablar de un fenómeno coordinado o planificado de acuerdo con un modelo previo. Una tarea pendiente a este respecto es el análisis metrológico de los edificios para la identificación de posibles módulos constructivos.

Lo que nos parece claro es que esta serie de asentamientos responden a una estrategia conjunta. $\mathrm{Su}$ distribución aseguraría una cobertura continua de las principales zonas de paso, así como de las conexiones entre ellas. Las características de las localizaciones definen un planteamiento muy homogéneo. La morfología de sus entornos inmediatos, junto con su capacidad de control visual, sugieren que la vigilancia sería su funcionalidad predominante. No obstante, en casos como La Dehesilla o La Lapa, hay que señalar la presencia en su contorno cercano de venas de óxidos de hierro. Como ya hemos apuntado en otro trabajo (Mayoral Herrera et al. 2010), este recurso ha sido objeto de una actividad extractiva tradicional, que documentalmente puede remontarse al menos a tiempos medievales. Cabe plantear pues la posibilidad de que ésta fuera otra motivación para elegir alguno de estos emplazamientos, aunque aún falta trabajo de campo por realizar para contrastar esta hipótesis.

Por otro lado, la homogeneidad en el diseño de las plantas y en las técnicas constructivas empleadas avalarían la idea de un programa sistemático, en el que además existe una jerarquización interna de diferentes entidades de poblamiento. Así, la importancia de las estructuras de Las Merchanas, junto con su emplazamiento en un punto clave para la circulación a través del corredor del Guadamez, sugieren que algunos de estos asentamientos fortificados actuarían como centros de referencia en la articulación de la ocupación del valle. Resta por valorar con un mayor detenimiento qué relación pueden tener estos sitios con otro asentamiento ya citado, el Santo de Valdetorres, que se localiza justamente en la confluencia entre el Guadamez y el Guadiana. Como ya se ha dicho, en este lugar se ha documentado un amplio conjunto de materiales de cronología republicana, que en opinión de su excavador corresponden a un asentamiento militar.

Por su parte, El Castillo del Portugués 1 y 2, que valoramos como partes de una única unidad de asentamiento, podrían definir otro nodo de esta trama, actuando como nexo entre el corredor del OrtigasGuadamez y el paso a través de las sierras de Arrozao y Lapa. Según el Mapa Topográfico Nacional editado en 1939, por la vaguada que separa ambas fortificaciones discurría el camino de Valle de la Serena a Cabeza Redonda, ya en el entorno de Don Benito, pasando por el Puerto de la Cabra. Dicho camino conduce al área de influencia de Magacela.

Es bien conocida la gran entidad de este asentamiento, precisamente durante el período tardorrepublicano (Ortiz Romero y Rodríguez Díaz 2004: 8893). Este sitio (Figs. 17 y 18) es de hecho considerado como un oppidum, cuyo surgimiento hay que entender dentro de los cambios que produce la injerencia romana en la estructuración territorial. Con una superficie de más de 7 hectáreas y un emplazamiento de alto valor estratégico, este enclave posee un complejo y monumental sistema defensivo, cuyas técnicas constructivas se asemejan en mucho a las de las fortificaciones de altura. Las estratigrafías del sitio plantean una datación entre finales del II e inicios del I a. C para estas murallas. 


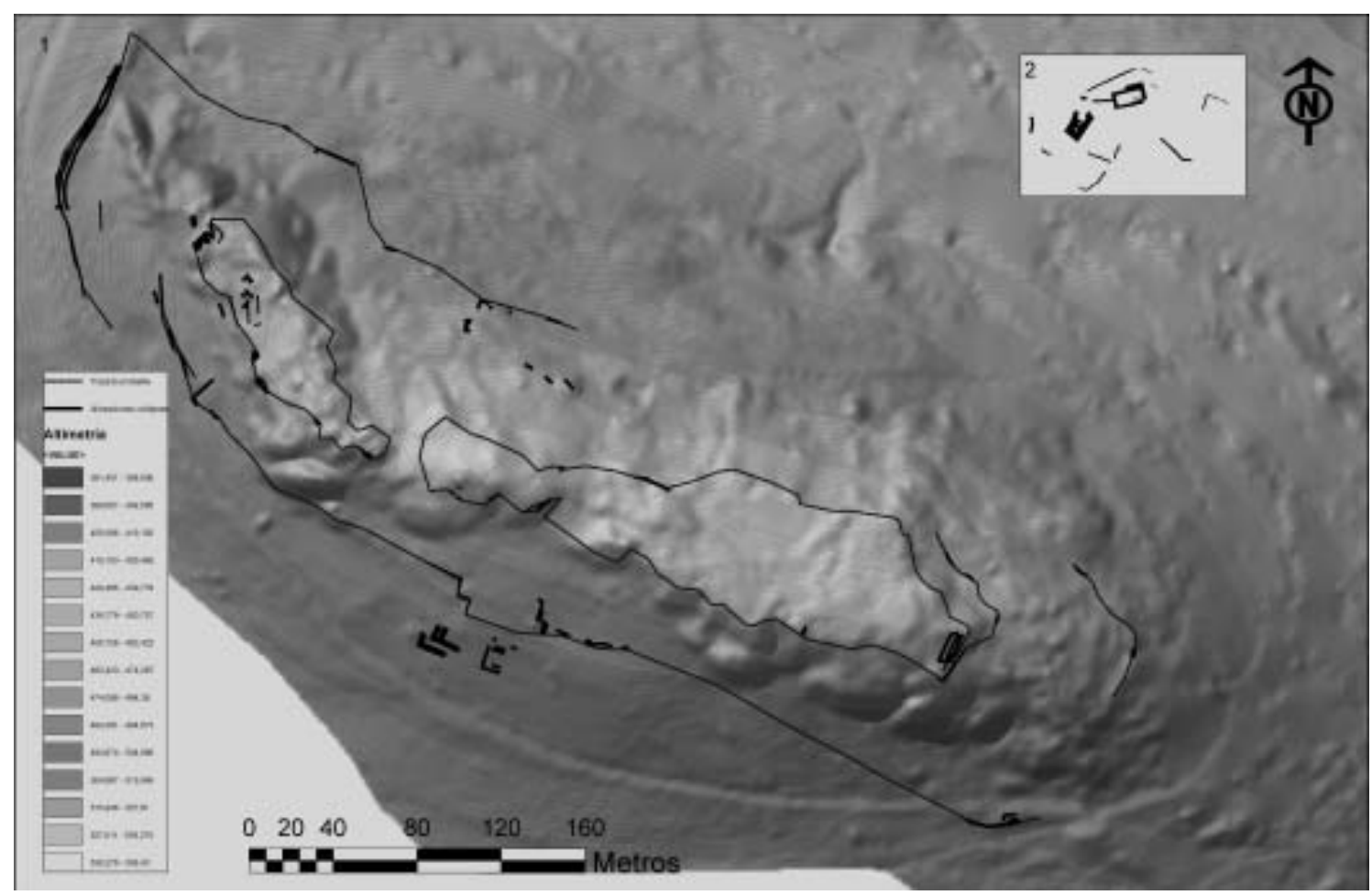

Figura 17. Modelo topográfico del cerro del castillo de Magacela, con indicación de las estructuras ciclópeas y el trazado probable de los recintos amurallados. En recuadro y a la misma escala, planta de Las Merchanas.

Lo que planteamos por tanto es que esta trama de fortificaciones no tiene sólo como finalidad ejercer un control sobre la ruta que conduce al Guadiana (Valdetorres-Medellín) a través del Guadamez, sino que está concebida además para resguardar la aproximación a Magacela por un itinerario secundario, que cruzando las sierras de La Lapa permitiría adentrarse en su área de influencia por la puerta trasera y eludiendo el control que ejerce este gran enclave amurallado sobre la cuenca del Ortigas.

Más problemático, en nuestra opinión, resulta que pueda hacerse extensiva la pertenencia a este sistema de los recintos y fortificaciones ciclópeas que se extienden por los llanos del fondo de esta última. La cronología inicial de este tipo de ocupaciones ha sido establecida, principalmente a partir de los resultados de la excavación de Hijovejo, en torno al primer cuarto del siglo i a. C. (Ortiz y Alonso, 2004: 82). Por nuestra parte la experiencia que van aportando sondeos realizados en los últimos años, en casos como Cerro del Tesoro o Recinto de Cancho Roano, parece definir con claridad una secuencia corta de ocupación algo más tardía, entre el cambio de Era y las primeras décadas del siglo I d. C. Existen por otra parte diversos argumentos, que sería largo de exponer aquí, que nos inclinan a considerar estas construcciones como parte de un proceso de colonización agrícola, que podría haber sido impulsado desde el núcleo de Iulipa. Apuntamos aquí la posible relación entre el surgimiento de este núcleo y la eclosión de los recintos de llano y otros fenómenos como la actividad cultual de la Cueva del Valle. El problema a este respecto es que contamos con muy escasas referencias para definir la entidad y cronología de este enclave, y aún menos para asegurar su localización exacta (tradicionalmente establecida en Zalamea de la Serena). Aunque no es el propósito central de este trabajo, nos parece oportuno mencionar en este sentido las ideas apuntadas en su día por García y Bellido respecto a la fecha fundacional cesariana o augustea de Iulipa (García y Bellido 1956: 20; García y Bellido y Menéndez Pidal 1963: 7-10). No obstante, en contra de esta atribución hay que citar el trabajo de Stylow (1991: 22), quien la considera un núcleo de status peregrino hasta su promoción Flavia.

Respecto a la perduración en el tiempo de las fortificaciones de altura, la hipótesis que se plantea es que algunas permanecen ocupadas al menos has- 

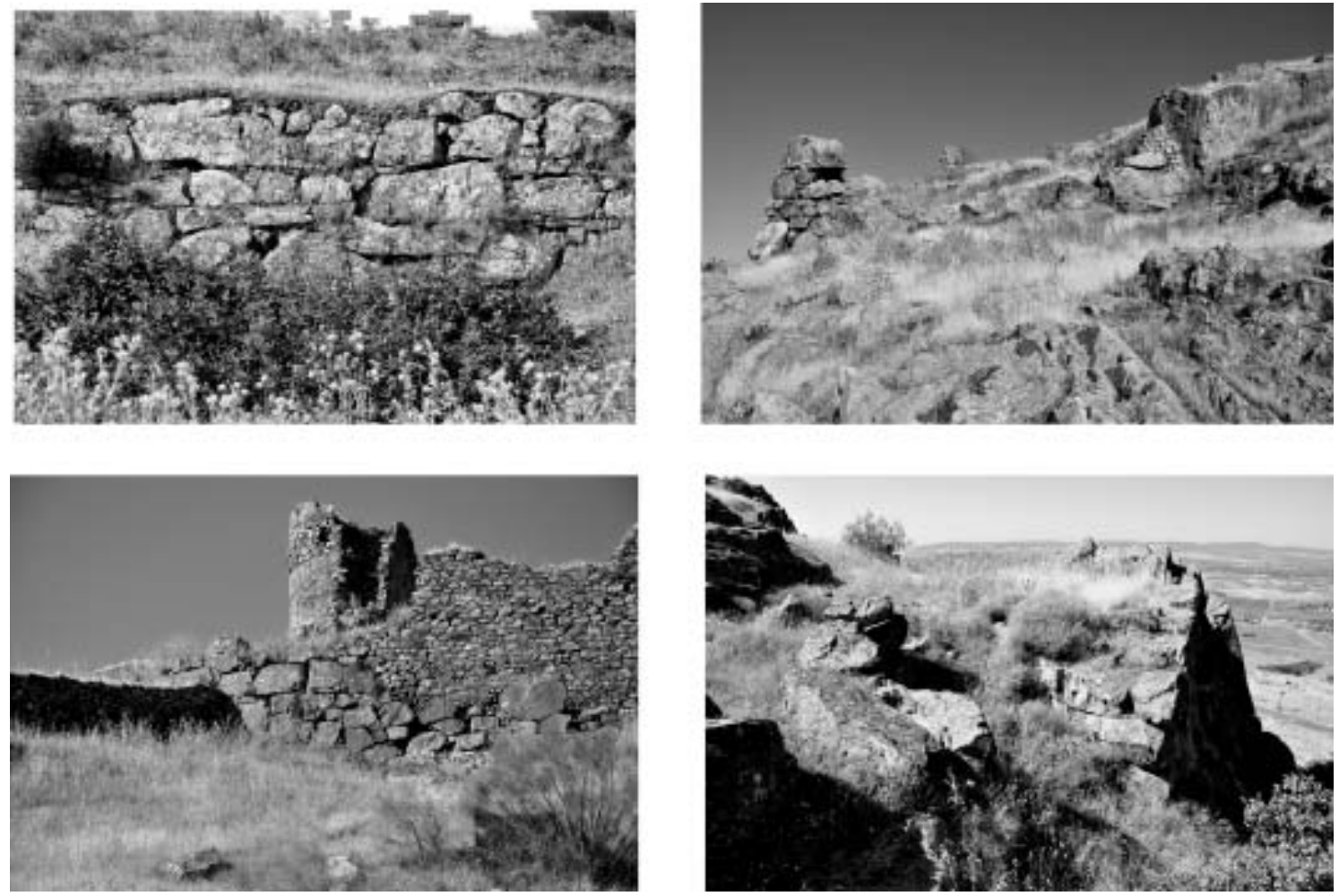

Figura 18. Diversos aspectos de las fortificaciones ciclópeas de Magacela. Fotografía: Victorino Mayoral.

ta mediados del siglo I d. C. Aquellos sitios más inaccesibles y con entornos más escarpados, como sierra del Portugués 1 y 2, Puerto de la Cabra o La Lapa, parecen detener su secuencia en una etapa anterior. En cambio, son precisamente los casos que presentan un valor medio de la pendiente más bajo y una mayor prominencia en su entorno inmediato los que han ofrecido material de época imperial. Así, tanto Ermita de San José como Castillejo del Moro cuentan con espacios de tierra arable y proximidad a cursos de agua. Sin embargo, a tenor de lo que pone en evidencia el registro superficial, no parece que se haya tratado de ocupaciones de gran entidad. Dentro de este último grupo, Merchanas podría haber pervivido como un enclave de tipo aldeano, ofreciendo el gran atractivo de contener la secuencia completa del proceso de implantación y consolidación del dominio romano en estas tierras.

\section{AGRADECIMIENTOS}

Queremos agradecer en primer lugar a Luis y Pedro Llanos, propietarios de la finca en la que se localiza el asentamiento de Las Merchanas, su amable disposición a facilitar el desarrollo de los trabajos. En las tareas de campo prestó una valiosa ayuda D. Antonio Domínguez. José Ángel Martínez del Pozo colaboró activamente en el proceso de elaboración de los modelos digitales y la planimetría de Las Merchanas. Agradecemos también a Luis Berrocal las valiosas indicaciones para la clasificación y datación del material cerámico. Igualmente damos las gracias a Antonio Pizzo por sus comentarios e impresiones respecto a la técnica constructiva de las fortificaciones. Gracias también a Tomás Cordero por sus útiles indicaciones sobre la bibliografía referente a la epigrafía romana de Iulipa.

\section{BIBLIOGRAFÍA}

Adroher, A., López Marcos, A. (eds.) 2004: El territorio de las altiplanicies granadinas entre la prehistoria y la edad media. Arqueología de la Puebla de Don Fadrique (1995-2002), Granada.

Adroher, A. M., Caballero, A., Sánchez Moreno, A., Salvador, J. A., Brao, F. J. 2006: «Estructuras 
Defensivas Tardo-Republicanas en el Ámbito Rural de la Bastetania». En A. Morillo Cerdán (ed.), Arqueología militar romana en Hispania II: producción y abastecimiento en el ámbito militar. León, 625-638.

Ainsworth, S.; Thomason, B. 2003: Where on Earth are We?. The Global Positioning System (GPS) in archaeological field survey, English Heritage Ordnance survey. Accesible on-line: http://www. english-heritage.org.uk/publications/gps-in-archaeological-field-survey/. Fecha de acceso: 15/ $11 / 2011$.

Alvarado, M., Molano, J. 1995: «Aportaciones al conocimiento de las cerámicas comunes altoimperiales en Augusta Emerita: el vertedero de la C/ Constantino». En Ceràmica comuna romana d'època Alto-Imperial a la Península Ibèrica. Estat de la quesito, Ampurias, 281-297.

Barandillo, A., Quirós, R. 1996: «Proyecto regente. Una nueva red geodésica nacional». Física de la Tierra 8, 23-38.

Berrocal Rangel, L. 1998: La Baeturia. Un territorio prerromano de la Baja Extremadura, Diputación Provincial de Badajoz. Departamento de $\mathrm{Pu}$ blicaciones, Badajoz.

Brotóns Yagüe, F., Murcia Muñoz, A. 2008: «Los castella tardorrepublicanos romanos de la cuenca alta de los ríos Argos y Quípar (Caravaca, Murcia). Aproximación arqueológica e histórica». En M. P. García-Bellido; A. Mostalac; A. Jiménez (eds.), Del imperium de Pompeyo a la auctoritas de Augusto. Homenaje a Michael Grant. Consejo Superior de Investigaciones Científicas. Madrid, 49-66.

Bustamante Álvarez, M. 2010: «Tradición versus innovación: análisis del instrumentvm domesticvm en el ámbito rural lusitano. El ejemplo del «Cerro del Tesoro» (La Serena, Badajoz)». En V. Mayoral; S. Celestino (eds.), Los paisajes rurales de la romanización: arquitectura y explotación del territorio. Actas de la Reunión Científica celebrada el Museo Arqueológico de Badajoz, noviembre de 2008. Ediciones la Ergástula, Madrid.

Campana, S. 2006: «DGPS e mobile GIS per l'archeologia dei paesaggi». En S. Campana; R. Francovich (eds.), Laser scanner e GPS: paesaggi archeologici e tecnologie digitali 1, atti del workshop, 3 marzo 2005 Grosseto. Edizioni all'Insegna del Giglio. Florencia.

Camilli, A. 1999: Ampullae. Balsamari ceramici di età ellenistica e romana, Roma.

Diosono, F. 2005: «El «castellum» romano del Cerro del Trigo (Puebla de Don Fadrique, Granada) y el control del territorio en la época republicana». Archivo Español de Arqueología 191, 119128.

Fabião, C. 2002: «Os chamados castella do sudoeste: arquitectura, cronología e funçoes». Archivo Español de Arqueología 75, 177-193.

García y Bellido, A. 1956: «Excavaciones en Iuliobriga y exploraciones en la región cántabra». Noticiario Arqueológico Hispánico 5, 218-245.

García y Bellido, A.; Menéndez Pidal, J. 1963: El distylo sepulcral romano de Iulipa (Zalamea). Consejo Superior de Investigaciones Científicas, Madrid.

García Sanjuán, L. 2004: «La prospección arqueológica de superficie y los SIG». En J. C. Martín De La Cruz; A. M. Lucena Martín (eds.), I Encuentro Internacional de Informática Aplicada a la Investigación y la Gestión Arqueológicas (5-7 de mayo de 2003). Universidad de Córdoba, Córdoba, 185-210.

García Sanjuán, L., Wheatley, D. 2003: «Obtención de micro-topografías de alta precisión de yacimientos arqueológicos mediante DGPS». Mapping 89, 94-98.

Haba Quirós, S. 1998: Medellín romano. La Colonia Metellinensis y su territorio. Diputación Provincial de Badajoz, Badajoz.

Heras Mora, F. J. 2009: «Fundaciones militares en el origen de la ciudad lusitana: nuevos datos para la reflexión». En P. Mateos Cruz; S. Celestino Pérez; A. Pizzo (eds.), Santuarios, oppida y ciudades: arquitectura sacra en el origen y desarrollo urbano del Mediterráneo Occidental. Instituto de Arqueología de Mérida y Consorcio de la Ciudad Monumental de Mérida, Mérida, 299-308.

Heras Mora, F. J., Bustamante, M. 2007: «Contribución al estudio de las ánforas tardorrepublicanas del enclave militar de «El Santo» de Valdetorres». Vipasca, Arqueología e Historia 2-2, 318-324.

Hernández Hernández, F., Rodríguez López, M., Sánchez Sánchez, M. A. 1989: Excavaciones en el Castro de Vilasviejas del Tamuja (Botija, Cáceres). Editora Regional de Extremadura, Mérida.

Martínez del Pozo, J. A., Uriarte González, A., Mayoral Herrera, V.; Pecharromán Fuente, J. L. 2010: «Geospatial characterization of archaeological sites in La Serena region (Badajoz) by direct methods (DGPS): Capturing and analyzing data». En F. J. Melero; P. Cano \& J. Revelles (eds.), Fusion of Cultures. Abstracts of the XXXVIII Annual Conference on Computer Applications and Quantitative Methods in Archaeology, CAA 2010, Granada, 537-540. 
Mataloto, R. 2002: «Fortins e recintos-torre do Alto Alentejo: antecâmara da «romanização» dos campos». Revista Portuguesa de Arqueología 5, 161220.

Mataloto, R. 2004: «Fortins romanos do alto Alentejo: fotificação e povoamento na segunda metade do séc. I a.C». En P. Moret; M. T. Chapa Brunet (eds.), Torres, atalayas y casas fortificadas: explotación y control del territorio en Hispania (s. III $a$. de C.- s. I d. de C.).Casa de Velázquez; Servicio de Publicaciones de la Universidad de Jaén, Madrid-Jaén, 31-54.

Mayoral Herrera, V., Boixereu Vila, E. \& Roger Salguero, M. I. 2010: «Paisajes mineros en la comarca de la Serena entre la protohistoria y el período romano: estado de la cuestión y perspectivas futuras». En L. Gutiérrez Soler (ed.), Minería antigua en sierra Morena. Servicio de Publicaciones de la Universidad de Jaén, Jaén, 235-254.

Mayoral Herrera, V., Celestino Pérez, S. (eds) 2010: Los paisajes rurales de la romanización: arquitectura y explotación del territorio. Actas de la Reunión Científica celebrada el Museo Arqueológico de Badajoz, noviembre de 2008. Ediciones la Ergástula, Madrid.

Moret, P. 2004: «Tours de Guet, maisons à tour et petits établissements fortifi'es de 1'Hispanie républicaine: L' apport des sources littéraires». En P. Moret \& M. T. Chapa Brunet (eds.), Torres, atalayas y casas fortificadas: explotación y control del territorio en Hispania (s. III a. de C.- s. I d. de $C$.). Casa de Velázquez; Servicio de Publicaciones de la Universidad de Jaén, Jaén, 13-29.

Moret, P., Chapa, T. (eds.) 2004: Torres, atalayas y casas fortificadas. Explotación y control del territorio en Hispania (s. III a. de C.-s. I d. de C.). Servicio de Publicaciones de la Universidad de Jaén-Casa de Velázquez, Jaén.

Morillo, A., Cadiou, F., Hourcade, D. (eds.) 2003: Defensa y territorio en Hispania desde los Escipiones a Augusto. Coloquio celebrado en la Casa de Velázquez, 19-20 de marzo de 2001). Casa de Velázquez/Universidad de León, MadridLeón.

Ortiz, P., Rodríguez, A. 1998: «Culturas indígenas y romanización en Extremadura: castros, oppida y recintos ciclópeos». En A. Rodríguez (coord.), Extremadura Protohistórica: Paleoambiente, economía y territorio. Universidad de Extremadura, Cáceres, 247-278.
Ortiz Romero, P. 2006: «Arqueología de la sierra de las Pozatas: fortificación romana de un espacio estratégico». Antaño, revista de la Universidad Popular de Castuera 13, 6-9.

Parcero Oubiña, C., Fábrega Álvarez, P. 2006: «Diseño metodológico para el análisis locacional de asentamientos a través de un SIG de base Raster». En I. Grau (ed.), La aplicación de los SIG en la arqueología del paisaje. Universidad de Alicante, Alicante, 69-90.

Pizzo, A. 2010: «Técnicas Constructivas de los «recintos torres» de la comarca de La Serena». En V. Mayoral, V. y S. Celestino (eds.): Los paisajes rurales de la romanización: arquitectura y explotación del territorio. Actas de la Reunión Científica celebrada el Museo Arqueológico de Badajoz, noviembre de 2008. Ediciones la Ergástula, Madrid.

Rodríguez Díaz, A. 1996: El poblamiento prerromano en la Baja Extremadura. Cáceres: Universidad de Extremadura, Servicio de Publicaciones. Tesis doctoral defendida en 1987 en la Universidad de Extremadura.

Rodríguez Díaz, A., Ortiz Romero, P. 1989: «Poblamiento prerromano y recintos ciclópeos de $\mathrm{La}$ Serena, Badajoz». Cuadernos de Prehistoria y Arqueología de la Universidad Autónoma de Madrid 17, 45-65.

Rodríguez Díaz, A., Ortiz Romero, P. 2004: «La torre de Hijovejo: génesis, evolución y contexto de un asentamiento fortificado en La Serena (Badajoz)». En P. Moret; M. T. Chapa Brunet (eds.), Torres, atalayas y casas fortificadas : explotación y control del territorio en Hispania (s. III a. de C.s. I d. de C.). Casa de Velázquez; Servicio de $\mathrm{Pu}-$ blicaciones de la Universidad de Jaén, Jaén, 7798.

Stylow, A. 1991: «El Municipium Flavium V (-) de Azuaga (Badajoz) y la municipalización de la Baeturia Turdulorum». Studia Historica. Historia Antigua 9, 11-25.

Venegas Sanz, J. L. 1995: «Prehistoria y protohistoria». En J. Mora Aliseda; J. Suárez De Venegas Sanz (eds.) Don Benito. Análisis de la situación socio-económica y cultural de un territorio singular. Editora Regional de Extremadura, Don Benito, 137-173.

Wood, J. 1996: The geomorphological characterisation of digital elevation models. University of Leicester, Leicester. 